\title{
NUEVAS SERIES DEL COMERCIO EXTERIOR DE MÉXICO, 1870-1929
}

\author{
SANDRA KUNTZ FICKER * \\ Universidad Autónoma Metropolitana-Xochimilco (México)
}

\begin{abstract}
RESUMEN
El artículo se ocupa de reconstruir los valores anuales del comercio exterior de México en el período 1870-1929, la llamada era del capitalismo liberal. Además de las estadisticas oficiales de este país, utiliza las de sus principales socios comerciales: Estados Unidos, Gran Bretaña, Francia y Alemania. Evalúa la calidad y consistencia de las fuentes mexicanas y aplica criterios explícitos para rectificar las cifras oficiales y cubrir las brechas en la información disponible. Asimismo, propone una reagrupación de los valores del comercio que permite distinguir entre el intercambio de mercancías y los flujos de metálico.

N. de E.: Fecha de recepción del artículo en la Revista de Historia Económica: octubre, 2001.

Fecha de aprobación del artículo por el Consejo de Redacción: mayo, 2002.

* Este trabajo es el producto de una larga investigación, y como tal ha pasado por diversas versiones y se ha discutido en varios foros. En el camino he acumulado deudas que quisiera reconocer. Ante todo, deseo agradecer la generosa aportación de ideas e información de Paolo Riguzzi, quien leyó cada uno de los manuscritos. A Antonio Tena le debo el haberme sugerido el tema y haberme facilitado sus avances en esta línea de investigación. Versiones anteriores del trabajo se presentaron en el Centro de Estudios México-Estados Unidos de la Universidad de California, en San Diego; en la Universidad de California, en Irvine; en el Primer Encuentro de la Sociedad Cliométrica Latinoamericana (Cartagena de Indias, 1999); en el Coloquio sobre la reconstrucción de series económicas de largo plazo (México, CIDE, 2000), y en el seminario del mismo nombre en El Colegio de México. En estos eventos recibí valiosas sugerencias de los participantes, en particular de Edward Beatty, Stephen Haber, Adolfo Meisel, Jordi Maluquer, Carlos Marichal, Noel Maurer, Kevin Middlebrook, Carlos Newland, Jaime Rodríguez, Steven Topik y Eric Van Young. Para todos, mi sincero agradecimiento. Finalmente, deseo reconocer las importantes observaciones de dos evaluadores anónimos, que en mucho contribuyeron a mejorar la presentación final del artículo.
\end{abstract}


Como resultado, ofrece series completas del comercio de mercancías y de las transferencias de dinero en especie, así como un cálculo anual de la balanza comercial para todo el período.

\section{ABSTRACT}

This paper provides a reconstruction of the yearly values of Mexico's foreign trade within the period 1870-1929, the era of liberal capitalism. It uses the Mexican official statistics as well as those published by Mexico's main trading partners: the United States, Great Britain, France, and Germany. The article assesses de quality and consistency of the Mexican sources and applies explicit criteria to rectify the official figures and to fill the gaps in the available information. It also proposes a new breakdown of trade values, which allows distinguishing between commodity trade and specie movements. As a result, the article provides with complete annual series of commodity trade and specie flows, as well as a yearly estimate of the trade balance throughout the period.

JEL Classification: N16, N76, F10, F14.

Los historiadores económicos han debatido largamente acerca del papel que la integración al mercado mundial ha desempeñado en el crecimiento económico de las naciones. En el caso de América Latina, el debate ha conducido a visiones polarizadas: para algunos, esa integración marcó el inicio del crecimiento económico moderno; para otros, representó el origen del subdesarrollo y la dependencia. En el centro de este debate se encuentra la cuestión del comercio exterior como la primera y, por un tiempo, más importante forma de participación en el sistema económico internacional. Sin embargo, la falta de evidencia empírica confiable ha convertido este debate en una confrontación ideológica. Para salir de este impasse es necesario construir información sólida y verificable que contribuya a conocer la evolución del comercio exterior y a comprender su papel dentro de la economía mexicana en el largo plazo.

El propósito de este trabajo es reconstruir las series anuales del comercio exterior de México y evaluar la calidad y comparabilidad de las estadísticas mexicanas disponibles. El artículo se ocupa del período de 1870 a 1929. que comprende desde la primera apertura significativa de México hacia la economía internacional hasta la crisis y colapso del capitalismo liberal 
en el sistema mundial ${ }^{1}$. Esta cronología coincide con los estadios formativos del crecimiento económico moderno en México, y subraya entonces la continuidad por encima de la ruptura política que representó la revolución de 1910-1917. El artículo está dividido en cuatro secciones. La primera ofrece algunas consideraciones acerca de la reconstrucción de las estadísticas comerciales, así como los precedentes disponibles para el caso de México. La segunda y tercera secciones se dedican a la reconstrucción estadística de los valores anuales de las importaciones y exportaciones mexicanas, respectivamente, distinguiendo el comercio de mercancías de los flujos de metálico. En la última se utilizan las nuevas series para estimar la balanza de comercio de México a lo largo de los sesenta años que comprende el estudio.

La principal fuente utilizada en este ejercicio son las estadísticas oficiales de la época publicadas por los gobiernos de México y de sus principales socios comerciales. En lo que se refiere a estas últimas, se reunieron las series del comercio con México compiladas por los gobiernos de Estados Unidos, Gran Bretaña y Francia, y a partir de 1890, de Alemania ${ }^{2}$. A lo largo del artículo, y salvo aclaración explícita, se asume el punto de vista de México, de manera que las importaciones representan adquisiciones que este país hizo del exterior, en tanto las exportaciones constituyen ventas de México al mercado internacional.

\section{LA RECONSTRUCCIÓN DE LAS ESTADÍSTICAS DEL COMERCIO EXTERIOR}

En casi todos los países, las estadísticas comerciales representan el más antiguo y consistente cuerpo de información cuantitativa construido por una agencia gubernamental. El interés público en los flujos del comercio exterior se deriva de la importancia que éstos han poseído históricamente

${ }^{1}$ En algún sentido puede decirse que la primera apertura de México al comercio internacional tuvo lugar como consecuencia del fin del vínculo colonial. De hecho, en las décadas posteriores a la independencia. la importancia relativa del sector externo en la economía parece haber crecido como resultado de la caida del PIB. Ver Coatsworth (1990), pp. 135-137. La apertura a que me refiero aquí es, 'sin embargo, la primera que tuvo lugar en el marco de un proceso concomitante de crecimiento económico.

${ }^{2}$ Para el período más reciente, la información oficial de cada país se complementó con estadísticas publicadas por agencias internacionales, como League of Nations (1927-1928, 1929, 1930-1931). 
en la recolección de impuestos ${ }^{3}$. A diferencia de otros tipos de evidencia cuantitativa, las estadísticas comerciales recopiladas por el gobierno de un país tienen una ventaja única: pueden ser contrastadas con la misma evidencia tal como ha sido producida por fuentes desinteresadas: los gobiernos de los socios comerciales de ese país. Este rasgo particular nos permite evaluar su confiabilidad y su grado de precisión antes de ser utilizadas para el análisis histórico. Para ello, es un requisito esencial que las estadísticas comerciales sean (o se vuelvan) susceptibles de comparación internacional.

Pese a sus ventajas, el uso de las estadísticas del comercio para propósitos analíticos y de comparación internacional ha sido escaso hasta tiempos recientes. La razón de ello parece ser el escepticismo frente a datos colectados por diferentes Estados conforme a criterios disímiles y con grados de precisión muy desiguales. El primer intento sistemático por evaluar la calidad de estos datos en el plano internacional arrojó resultados optimistas. En términos generales, las estadísticas comerciales de los diferentes países no exhibían criterios arbitrarios ni un falseamiento deliberado. Muchas de las discrepancias que se observaban en los mismos datos publicados por distintos países poseían un origen legítimo identificable, y por lo tanto eran susceptibles de corrección y ajuste ${ }^{4}$. Sin embargo, casi simultáneamente se manifestó una percepción opuesta, que bien puede sintetizarse en esta afirmación de Oskar Morgenstern, su principal promotor: «incluso para la descripción ordinaria, que en sí misma no intenta ser una aplicación de teoría económica de alto poder, las estadísticas son tan extremadamente malas que para la mayoría de los propósitos deben ser rechazadas» ${ }^{5}$.

Los pocos intentos de lidiar con las estadísticas latinoamericanas reforzaron esta visión negativa. Al menos dos artículos de amplia difusión condenaron a un fracaso seguro cualquier exploración en este terreno. Mientras reconstruía la balanza comercial de Estados Unidos, Matthew Simon recha-

${ }^{3}$ De hecho, cuanto más limitada la capacidad administrativa de un Estado, tanto mayor la importancia de controlar los flujos del comercio exterior para disponer de los ingresos aduanales. Helleiner (1972), p. 112.

${ }^{4}$ Allen y Ely (1953). De acuerdo con ellos, las estadísticas comerciales de las antiguas naciones europeas son más confiables que las de los jóvenes países latinoamericanos, no obstante lo cual éstas se encuentran en un margen aceptable de confiabilidad. Véase el ensayo de Taylor y Rothrock en la misma obra. Para una evaluación más reciente, y con herramientas más sofisticadas, de las estadísticas comerciales de más de rreinta países ver Tena (1992).

5 Morgenstern (1963), p. 143. Para una crítica reciente a este juicio ver Federico y Tena (1991). 
zó el uso de las fuentes oficiales mexicanas para corregir los datos estadounidenses mediante un dictamen categórico: «Las estadísticas compiladas por el gobierno mexicano sobre las importaciones de Estados Unidos eran inadecuadas» ${ }^{6}$. Más influyente aún fue el artículo de Platt sobre las estadísticas comerciales latinoamericanas previas a la Primera Guerra Mundial. Para rematar una evaluación claramente desfavorable de las fuentes disponibles, Platt utilizó una cita elocuente: «es preciso tener una buena dosis de fe para sentir que se está razonando sobre una base segura» ${ }^{7}$. Aunque es imposible saber hasta qué punto tales juicios disuadieron a los estudiosos dentro del contexto latinoamericano, lo cierto es que muy pocos esfuerzos se han destinado a la reconstrucción de las estadísticas comerciales de los países de la región desde una perspectiva histórica ${ }^{8}$.

El caso de México no es particularmente alentador. Inés Herrera publicó en los años setenta las pocas cifras disponibles para el período 1821-1874 ${ }^{9}$. Su trabajo testifica lo que queremos decir por «era preestadística»: dentro de un lapso de cincuenta y tres años, sólo en once se publicaron estadísticas más o menos completas del comercio exterior (1821-1828, 1856 y 1872-1874), que en algunos casos son de dudosa precisión ${ }^{10}$. Un acercamiento más comprensivo se debe a Bernard Kapp, quien utilizó por primera vez fuentes de los socios comerciales de México para presentar la evolución del comercio entre 1825 y $1911^{11}$. Desafortunadamente, este trabajo, publicado hace más de veinte años en París, es prácticamente desconocido en México. Una publicación más reciente, pero también de escasa difusión, utiliza series elaboradas por el autor para analizar el desempeño del sector externo en la economía porfiriana. Sin embargo, no se exponen en él los criterios con que estas series se construyeron, y los resultados son, en algunos años, extremadamente divergentes de los

6 Simon (1960), p. 636.

${ }^{7}$ Citado en Platt (1971), p. 129.

${ }^{8}$ Uno de los pocos ejemplos disponibles es el de Colombia. Entre los países de desarrollo tardío el ejercicio más completo de reconstrucción se realizó en España, en donde se dispone de series para el período 1821-1935. Para Colombia véase Rodríguez y McGreevey (1970) y Ocampo (1980). Para España ver Prados de la Escosura (1986) y Tena (1985).

9 Herrera Canales (1977).

${ }^{10}$ Una crítica de las cifras mexicanas disponibles hasta 1870 , acompañada de un esfuerzo de rectificación apoyado en fuentes de los socios comerciales, es Ibarra Bellón (1998), parte I.

${ }^{11}$ Kapp (1974). El trabajo acusa ciertas debilidades, como el no hacer explícitos los criterios de recopilación y el que la presentación de los datos es un tanto rudimentaria (las cifras se incluyen en la moneda original, sin intentar uniformarla para propósitos de agregación o comparación). Se trata, sin embargo, de un ejercicio valioso porque además de introducir una visión de largo plazo, se ocupa de los cincuenta años posteriores a la independencia, para los que se dispone de muy poca información. 
que arroja una reconstrucción sistemática a partir de las fuentes disponibles ${ }^{12}$. En fin, hasta este momento no se ha realizado un ejercicio de reconstrucción para el lapso 1910-1930, y los pocos trabajos que abordan el problema del comercio exterior en este período se basan en las fuentes mexicanas ${ }^{13}$.

La compilación de datos más conocida es el volumen sobre comercio exterior de las Estadísticas económicas del porfiriato ${ }^{14}$. Se trata de una fuente útil que reúne las cifras oficiales disponibles y las desagrega por productos, países y aduanas. Las series de importación abarcan sólo el período 1892-1911, pero las de exportación cubren los años de 1877 a 1911. Sin embargo, en ambos casos las series adolecen de varias deficiencias, que van desde problemas de conversión y tipo de cambio en el caso de las importaciones hasta criterios erróneos en la agregación que derivan en falsos totales en el caso de las exportaciones. Algunos de estos problemas, a los que nos referiremos en su oportunidad, disminuyen la utilidad analítica de las series y su comparabilidad en el plano internacional. Como se sabe, este volumen es la base de la más importante interpretación histórica sobre el período, la Historia moderna de México, y también la fuente más utilizada por los investigadores que se ocupan de la evolución económica del país durante el porfiriato ${ }^{15}$.

El problema que se trasluce en las evaluaciones pesimistas o en las escasas aproximaciones a las estadísticas del comercio exterior es que la evidencia cuantitativa que nos legó el pasado difícilmente se encuentra «lista para usarse». De una u otra forma, ésta debe ser construida o reconstruida mediante criterios cualitativos y una selección informada para hacerla útil para la interpretación histórica. La reconstrucción de estadísticas his-

12 Catao (1991). Algunos trabajos recientes se han ocupado de reconstruir series de largo plazo del comercio bilateral de México con los Estados Unidos. Ver Salvucci (1991), para el período 1823-1883; Beatty (2000), para los años 1880-1923, y Kuntz Ficker (2001), para el período 1870-1929. Los dos primeros trabajos se basan enteramente en las fuentes estadounidenses, en tanto el último utiliza también las de procedencia mexicana y propone algunos criterios distintos para la reconstrucción. Por otra parte, Lorey (1990), pp. 366-67, ofrece cifras oficiales de Estados Unidos para el comercio total con México a partir de 1900. Finalmente, en Mitchell (1983 y 1992) se incluyen valores anuales del comercio por país a partir de fuentes oficiales.

${ }^{13}$ Lerman (1989 y 1990); Catao (1992); Cárdenas (1987).

14 El Colegio de México (1960). Los valores anuales del comercio de todo el período conforme a las fuentes oficiales se reproducen en Estadísticas bistóricas (1985), vol. II, pp. $661-727$.

15 Véase Cosío Villegas (1955-1972) y Rosenzweig (1989). También John Coatsworth hace uso de estas series para estudiar el sector externo durante el porfiriato. Ver Coatsworth (1990), p. 143. 
tóricas es un proceso analítico complejo, que requiere herramientas metodológicas y cierto conocimiento del contexto histórico, tanto de las condiciones internas del país como de los patrones y rutas del comercio internacional.

La reconstrucción que aquí se propone está basada en la comparación entre las estadísticas oficiales de México y las de sus principales socios comerciales. Para este propósito se han recopilado las series anuales del comercio con México publicadas por Estados Unidos, Gran Bretaña, Francia y Alemania. (Para simplificar, en adelante las fuentes oficiales de cada país se designan como MX, EU, GB, FR y DT, respectivamente.) En promedio, el intercambio con estos cuatro países representó alrededor del 90 por 100 del comercio de México con el exterior a lo largo de todo el período, y ofrece por tanto una cobertura amplia para la estimación de los flujos totales. Siempre que fue posible se recopiló tanto el valor total del comercio anual como las cifras desglosadas por rubros y productos, pues los datos desagregados han probado ser de gran utilidad en la identificación de las discrepancias entre las fuentes mexicanas y las de cada uno de sus socios comerciales ${ }^{16}$. Vale la pena hacer dos aclaraciones antes de explicar el procedimiento adoptado en la reconstrucción. En primer lugar, no está de más reiterar que se trata aquí de reconstruir los valores anuales del comercio, y que éstos son una función de dos variables: precio y cantidad. Naturalmente, esta reconstrucción no permite discernir cuál de las variables incidió en cada momento sobre el valor anual del comercio, ejercicio complejo que requiere un acercamiento distinto. En segundo lugar, es preciso aclarar que en el registro del comercio de cada país con México (y de México con sus socios) puede permanecer oculto el origen o destino final de algunos intercambios que se realizaron a través del país en cuestión ${ }^{17}$. Lo que es posible reconstruir a partir de estas fuentes es, entonces,

${ }^{16}$ De acuerdo con Kane y Weiss, «probablemente se encontraría que las principales fuentes de incomparabilidad radican en el tratamiento de un número limitado de bienes». *Compilation», en Allen y Ely (1953), p. 24.

${ }^{17}$ Aunque los principales socios de México utilizaban en la distribución del comercio por países el método de origen-destino, el criterio se aplicaba solamente cuando este dato era conocido, lo que significa que en los hechos pudo operar a veces el principio de país de consignación. Gran Bretaña adoptó formalmente este último criterio a partir de 1909. México solamente hizo explícitas las normas de recopilación de sus estadísticas comerciales en la década de 1920, aunque algunas de ellas pueden detectarse en las distintas versiones del Arancel de Aduanas. Parece ser que el criterio de procedencia y consignación prevaleció al menos desde 1872, pues representaba «la mayor garantía para el fisco y para el comercio de buena fe». Por las razones expuestas, es muy difícil trazar el recorrido de los intercambios desde el sitio de producción hasta el de consumo final. Allan y Ely (1953), pp. 283-284, 
el valor total de las transacciones anuales de México y la distribución visible del comercio entre los socios principales.

El primer paso de la reconstrucción consistió en uniformar las series del intercambio entre México y cada uno de sus socios de manera que todas expresaran el valor $\mathrm{f}$. $\mathrm{o}$. b. del comercio anual en dólares corrientes. Se dispuso entonces de dos series uniformes del valor anual del comercio bilateral (de importación o exportación, según el caso), para cada uno de los socios principales: la serie de procedencia mexicana y la compilada por el socio comercial. Cada par de series se sometió entonces a una comparación cuidadosa para observar el grado de similitud o divergencia que las cifras de ambas fuentes guardaban entre $\mathrm{si}^{18}$. Ello permitió evaluar en términos generales la calidad y consistencia de las cifras provistas por México y por cada uno de sus socios, e identificar etapas en la evolución del registro estadístico de los distintos países. Una vez hecho esto, fue posible profundizar en cada una de las series del comercio bilateral para reconocer las fuentes de discrepancia o de incomparabilidad. La identificación de las fuentes de distorsión permitió tomar decisiones acerca de la conveniencia de utilizar las series de México o las de sus socios en las distintas fases del período; acerca de los criterios que debían aplicarse para corregir las discrepancias observadas, y acerca de las hipótesis que debían asumirse para reconstruir los valores totales.

A partir de estas decisiones se construyeron series del comercio de importación y exportación de mercancías entre México y cada uno de sus socios principales. Por cuanto el comercio mexicano exhibió en este período una alta concentración geográfica, al sumar el valor del comercio con los principales socios se obtuvo un porcentaje elevado de su valor total. Resulta claro, sin embargo, que no se había obtenido aún este valor total. Para ello era necesario saber qué proporción del comercio había correspondido a los principales socios en cada año. La única forma de conocer esta proporción es recurriendo a las estadísticas mexicanas disponibles, a partir de las cuales se calculó la participación promedio de los socios para cada decenio. Cuando el dato de alguno de los socios faltaba, se descontó su

292, 302, 354-359; Sierra y Martínez (1973), p. 152. El Arancel y sus modificaciones hasta 1910 se reproducen en Dublán y Lozano (1877-1910), passim. Los criterios que México empleó en los años veinte se encuentran en Departamento de la Estadística Nacional (1932), p. 439.

${ }^{18} \mathrm{La}$ comparación procedió, naturalmente, sólo en los casos en que se dispuso de cifras de las dos procedencias. Cuando alguna faltaba, el análisis se limitó a la consistencia interna de la serie disponible. 
participación media decenal (conforme a las cifras MX) del porcentaje a partir del cual se estimó el valor total. Aunque el procedimiento no provee precisión absoluta, es el único asequible mientras no se disponga de una cobertura total del comercio de México a partir de las estadísticas de cada uno de sus socios en el mercado internacional. En el mismo sentido, resulta claro que la calidad de las cifras totales mejorará a medida que la cobertura se amplíe, de manera que disminuya el residuo que por ahora es preciso estimar. La metodología específica y los resultados de la reconstrucción de las importaciones y las exportaciones se presentan, con el detalle que permite el espacio de este artículo, en las siguientes páginas.

\section{LAS IMPORTACIONES}

Con el fin de ilustrar el camino seguido en la reconstrucción de las series de importación, el gráfico 1 presenta el resultado de comparar los valores del comercio bilateral entre México y cada uno de sus principales socios de acuerdo con las dos fuentes disponibles en cada caso. Como el propósito es evaluar en términos generales la calidad y comparabilidad de las fuentes originales, el gráfico ofrece datos brutos, es decir, tal como aparecen en las estadísticas oficiales ${ }^{19}$. Sólo dos ajustes necesarios se han aplicado a las cifras originales: todas se han convertido de la moneda original a dólares, y se han uniformado para expresar años fiscales hasta 1917 y años naturales a partir de entonces ${ }^{20}$.

${ }^{19}$ Las importaciones mexicanas proveen valores f.o.b., al igual que las exportaciones de los socios comerciales. Ello facilita la uniformación de las series de importación, pues evita tener que estimar costos de transporte y seguros para hacer comparables las series. Las cifras oficiales de México representan el valor declarado de las importaciones, en tanto las de los socios corresponden al valor declarado (valor actual para Francia, valor oficial revisado anualmente desde 1901 para Alemania) de las exportaciones netas (comercio especial para Francia y Alemania) dirigido a México (valores f.a.s. para Estados Unidos; f.o.b. para los demás). F.o.b. = free on board, excluyendo costos de transporte y seguro. F.a.s. $=$ free along side, que incluye esos costos hasta el lugar de exportación dentro de Estados Unidos. Para las definiciones ver Henius (1946), passim, y Allen y Ely (1953), pp. 85-88. Acerca de los métodos de valoración en las estadísticas FR y DT véase Direction Générale (1872-1931) (1973), p. vi; Allen y Ely (1953), pp. 291, 355, 370.

20 Para las tasas de cambio utilizadas véase apéndice. En cuanto a los períodos anuales, se utiliza el sistema mexicano del año fiscal (que inicia el 1 de julio) hasta 1917, pues a partir de entonces la mayor parte de los países converge en el uso de años naturales. Hasta entonces Estados Unidos usa los mismos períodos fiscales que México, aunque los nombra según la terminación y no el inicio del año. Gran Bretaña y Francia usan años calendario, que se convirtieron a fiscales mediante el promedio simple de cada par de años 


\section{GRÁFICO 1}

Porcentaje de discrepancia en los valores anuales del comercio entre las estadísticas de México y las de sus principales socios comerciales.

Importaciones, 1870-1929

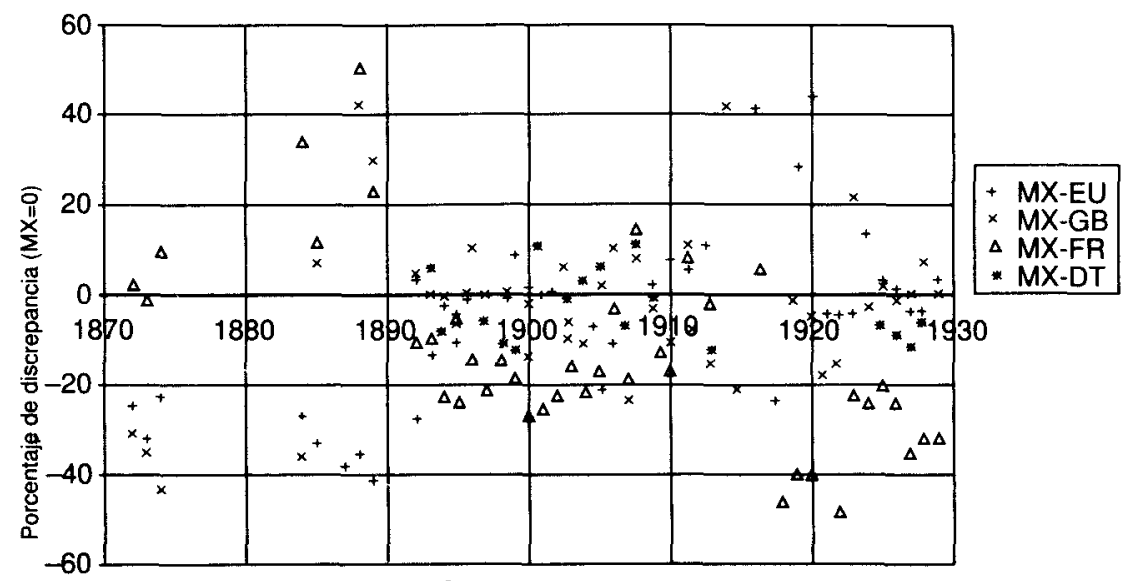

Coeficiente de correlación y $\mathrm{R}^{2}$ de cada par de series:
MX-EU: $\mathrm{CC}=0,971$
$M X-G B: C C=0,918$
$M X-F R:$

$$
\begin{array}{rlrl}
C C & =0,695 \quad M X-D T: C C & =0,991 \\
R^{2} & =0,483 & R^{2} & =0,982
\end{array}
$$$$
R^{2}=0,943
$$$$
R^{2}=0,842
$$

Fuentes: Estadísticas oficiales de México y de sus socios comerciales. Para fuentes, véase bibliografía.

El gráfico ilustra el porcentaje de discrepancia entre las cifras mexicanas y las de sus cuatro socios principales para cada uno de los años disponibles entre 1870 y 1929 , sumando un total de 148 observaciones ${ }^{21}$. La línea cero representa las cifras mexicanas, de manera que los puntos sobre esta línea significan una identidad perfecta con las cifras del socio en cuestión; los puntos por encima de la línea significan que las cifras de los socios son superiores a las $\mathrm{MX}$, y los puntos por debajo, que son inferiores a éstas en ese año. ¿Como debe interpretarse la información contenida en el gráfico? Podemos establecer un rango de confiabilidad mínima alrededor

naturales. Alemania ofrece años fiscales que empiezan el 1 de abril. La conversión se hizo usando el 75 por 100 del primer ano y el 25 por 100 del segundo.

${ }^{21}$ Se excluyeron de la comparación algunas cifras MX para la década de 1910, debido a que acusan una subestimación extrema y producen discrepancias muy grandes para ser contenidas en el gráfico. 
de \pm 20 por 100 , fuera del cual las discrepancias reflejan distorsiones severas en el registro estadístico de una u otra parte ${ }^{22}$. Las estadísticas mexicanas caen dentro de ese margen en 103 observaciones ( 70 por 100 del total), y en 84 de ellas (57 por 100 del total) muestran una comparabilidad aún mejor, manteniéndose dentro de un rango de confianza de 10 por 100 . Las discrepancias más severas y aleatorias se observan en los períodos $1870-1890$ y $1913-1922$, en tanto la mayor consistencia se presenta claramente en los años 1892-1912. El grado de comparabilidad varía también en relación con los países: la mejor es por mucho MX-DT, que exhibe una similitud casi completa entre 1890 y 1912. Esto habla bien de las estadísticas mexicanas recopiladas en ese período, pues las fuentes alemanas son consideradas entre las más confiables y precisas del mundo. En la medida en que las cifras EU y GB se aproximan a las MX durante estos años, puede pensarse que su registro del comercio con México es relativamente confiable a lo largo de todo el período (con las salvedades que se expondrán más adelante). En fin, el peor comportamiento se presenta en las cifras MX-FR, cuyas discrepancias rebasan en muchos años el margen de confiabilidad aceptado. Como se verá en lo siguiente, estas discrepancias poseen un origen identificable y pueden ser al menos parcialmente corregidas. Los coeficientes de correlación incluidos al pie de el gráfico confirman estas percepciones.

La comparación entre los pares de datos permite identificar tres etapas en el registro estadístico del comercio de importación en México: la primera, entre 1870 y 1892, es una fase preestadística, en la cual el registro del comercio es esporádico y en algunos casos acusa severas distorsiones. Debido a la falta de datos y a su dudosa confiabilidad, la reconstrucción del comercio en este período debe basarse en las estadísticas de los socios comerciales, rectificadas a partir de criterios definidos con ayuda de las fuentes mexicanas disponibles ${ }^{23}$. La segunda fase, entre 1892 y 1912, se ubica dentro de la etapa de madurez del régimen porfirista (1876-1911), en la que las esta-

${ }^{22}$ Tal rango es propuesto en Tena (1992) como el máximo aceptable para considerar que las series estadísticas de los distintos países son relativamente confiables y comparables entre sí.

${ }^{23}$ Entre 1870 y 1892 se dispone de datos MX para siete años fiscales: $1872-1874$, $1884,1885,1888$ y 1889 . Los tres años de 1872 a 1874 representan el mayor esfuerzo realizado en esta etapa por sistematizar el registro del comercio, y aunque las cifras podrían acusar cierta subestimación debida al contrabando, en general son relativamente consistentes y confiables. Esto no puede decirse, sin embargo, de ninguno de los otros años: en 1884 y 1885 se dispone sólo de datos semestrales de las importaciones, recopilados bajo circunstancias difíciles y con escasos recursos. En cuanto a las cifras conocidas para 1888 
dísticas comerciales se publican regularmente, siguen criterios estables y muestran una alta consistencia y calidad. En esta etapa pueden utilizarse los datos de fuentes $\mathrm{MX}$, ajustándolos a partir de las cifras que aportan los socios para descontar las importaciones de metálico y construir una serie completa del comercio de mercancías. La última fase, de 1913 a 1929, es una suerte de combinación de las dos anteriores: durante los años de la guerra civil (1911-1917) la compilación estadística es deficiente e irregular; a inicios de los años veinte ésta se ve severamente afectada por cambios en los criterios y las valoraciones, para recuperar luego cierta consistencia y regularidad. En estos años se ha optado por utilizar las series de los socios de México, rectificadas y complementadas a partir de las fuentes MX disponibles. Veamos cada una de estas etapas con mayor detalle.

\section{A) La era preestadística: $\mathbf{1 8 7 0 - 1 8 9 2}$}

Las distorsiones presentes en las pocas cifras $\mathrm{MX}$ disponibles se deben sobre todo al contrabando, que, de acuerdo con estimaciones oficiales, habría alcanzado alrededor del 15 por 100 del valor de las importaciones legales ${ }^{24}$. En el curso de los años ochenta, tres factores contribuyeron a disminuir el peso del tráfico ilegal: por un lado, la imposición de penas severas para los contrabandistas; por el otro, la creación, en 1885, de un cuerpo armado (la Gendarmería Fiscal) con amplias facultades para vigilar el territorio y detener a los infractores. Por último, la construcción de ferrocarriles, que al disminuir el costo del transporte creó incentivos para el comercio legal al mismo tiempo que facilitaba el control público sobre las rutas del comercio. Para los primeros años de 1890, la mayor capacidad del Estado para controlar el territorio y la disminución en las barreras arancelarias redujeron el contrabando a proporciones insignificantes desde el punto de vista estadístico ${ }^{25}$.

Del lado de los socios, una fuente importante de distorsión en las cifras del comercio con México se relaciona con la situación económica y la posición internacional de este país. En la década de 1870 México carecía de instituciones financieras, de un sistema de transporte eficiente y de cone-

y 1889 , existe seria controversia sobre si se trata de cifras en dólares o en pesos mexicanos. $\mathrm{Al}$ respecto ver Kuntz Ficker (2001), nota 14.

${ }_{24}$ Memoria de Hacienda (1879), p. 62, y Memoria de Hacienda... (1880), p. 1.

${ }^{25}$ Acerca de la política comercial y la reducción de las barreras impuestas al comercio ver Kuntz Ficker (2002). 
xiones regulares con el transporte internacional; además, sus relaciones diplomáticas con las principales potencias europeas estaban rotas ${ }^{26}$. Estos factores hicieron de Estados Unidos el principal intermediario en el comercio europeo con México, al punto que más del 30 por 100 de sus exportaciones brutas a México eran reexportaciones. Existen indicios de que la mayor parte de estas reexportaciones eran de origen británico, y que en las estadísticas GB este comercio aparecía como destinado a los Estados Unidos ${ }^{27}$. En consecuencia, pese a que la práctica usual es considerar sólo el comercio neto de cada país, la reconstrucción del valor total de las importaciones mexicanas entre 1870 y 1880 incluye, sin riesgo de duplicación, las reexportaciones de Estados Unidos a México ${ }^{28}$. A partir de los años ochenta las pautas del comercio internacional de México sufrieron cambios significativos, relacionados con la reanudación de relaciones diplomáticas con los países europeos, la construcción de ferrocarriles y el establecimiento de instituciones bancarias. Estos y otros avances produjeron un aumento del comercio directo entre México y sus socios europeos, que se reflejó en la drástica disminución de las reexportaciones estadounidenses y en un registro más preciso de los flujos comerciales destinados a México en la contabilidad de sus socios principales ${ }^{29}$. En consecuencia, con excepción del comercio francés, que se aborda en seguida, a partir de 1880 se ha asumido el supuesto convencional de considerar tan sólo el comercio neto de cada país en la reconstrucción de los valores totales de las importaciones mexicanas.

Las cuentas comerciales francesas ofrecen una dificultad mayor, debida a criterios de compilación (la separación entre comercio general y comercio

${ }^{26}$ Acerca de las relaciones internacionales de México en el porfiriato temprano ver Katz (1986), pp. 26-32, y para una interpretación diferente, Riguzzi (1992).

${ }^{27}$ En sus estimaciones del comercio de importación a México entre 1824 y 1862, Araceli Ibarra asume que las reexportaciones de Estados Unidos a México procedían en su totalidad de Gran Bretaña. Ibarra Bellón (1998), cuadro 23. Las estadísticas británicas registraban el destino del comercio siempre y cuando éste era conocido; en caso contrario se estipulaba el país de consignación (en este caso Estados Unidos). De acuerdo con este supuesto, las discrepancias observadas en el gráfico 1 en las cifras MX-GB antes de 1892 se deberían a un subregistro de las exportaciones británicas que fueron destinadas a México pero presumiblemente consignadas a Estados Unidos y que, en cambio, fueron registradas correctamente en las fuentes MX.

${ }^{28}$ En el comercio por países estas reexportaciones deberían acreditarse en su mayor parte a Gran Bretaña. Por otra parte, en el caso de este último país se ha seguido el criterio convencional de utilizar solamente el comercio neto, pues las reexportaciones son de menor importancia (disminuyeron del 15 al 4 por 100 a lo largo de la década) y su origen es más difícil de identificar, por lo que el riesgo de duplicación es mayor.

${ }^{29}$ Las reexportaciones de Estados Unidos a México sumaron el 18 por 100 del total en 1880 , y menos del 11 por 100 a partir de 1885 . 
especial) que impiden una distinción llana de lo que constituye el comercio neto y disminuyen por ello su comparabilidad ${ }^{30}$. En esta reconstrucción se ha adoptado el criterio de agregar a las exportaciones FR del comercio especial aquellos insumos (principalmente algodón y lana) que se incluyeron sólo en la cuenta del comercio general pero que muy probablemente formaban parte del comercio neto de Francia con México. La pertinencia de este criterio se ha corroborado mediante una comparación del intercambio entre los dos países producto por producto según las estadísticas FR y MX para el período 1892-1912, en que estas últimas mostraron la mayor consistencia y precisión.

Las distorsiones que se observan en la década de 1880 se deben a dos factores principales: del lado de México, el contrabando, al que ya me he referido, y del lado de los socios, la deficiencia en el registro EU de las exportaciones a México ${ }^{31}$. Esta deficiencia se debe a que entre 1882 y 1893 las estadísticas EU no consideraban las exportaciones realizadas por tierra ${ }^{32}$. Esta falta tuvo un impacto progresivamente mayor sobre el registro del comercio a medida que se avanzó en el tendido de los ferrocarriles entre el centro de México y la frontera norteamericana. Como las cifras mexicanas están también subestimadas debido al contrabando, es impracticable utilizarlas para suplir la deficiencia en las fuentes EU. El procedimiento empleado ha sido, en cambio, aumentar las cifras EU en una proporción igual a la del comercio que, según las fuentes $M X$, se introdujo a través de la frontera entre los dos países. El único supuesto

30 El problema radica en el criterio utilizado en las estadísticas francesas para distinguir entre comercio especial y general. De acuerdo con las definiciones oficiales, el primero incluye todas las mercancías producidas en el país, o «nacionalizadas» mediante el pago de derechos, que se enviaban al exterior, pero excluye el valor de los insumos importados temporalmente (libres de derechos) para ser procesados por la industria francesa, registrando únicamente el valor agregado en el producto final. El valor de esos insumos se computa, en cambio, en el comercio general. Ello significa que el valor de los insumos utilizados en la producción de artículos exportados a México se ha excluido del comercio especial. En consecuencia, para obtener el valor del comercio neto es preciso sumar el valor de estos insumos al del comercio especial. Acerca de este y otros criterios véase Arnauné (1911), p. 303 y passim; Institut International d'Agriculture (1914), passim.

${ }^{31}$ Existe aún otro defecto, aunque de menor importancia, en las estadísticas EU para los años de 1870, relacionado con la forma en que se valoraron las exportaciones domésticas de ese país. Tal deficiencia, y el procedimiento utilizado para corregirla, se exponen en Kuntz Ficker (2001).

32 \&En ausencia de una ley que prescriba la recolección de estadísticas de exporiaciones hacia territorio extranjero adyacente mediante los ferrocarriles desde 1882 , los datos sobre las exportaciones que se dan aquí son muy incompletos y en gran parte subestimados». Statistical Abstract, núm. 12 (1889), p. 69. 
implícito en este procedimiento es que las dimensiones del comercio ilegal no registrado en fuentes mexicanas fueron similares en todo el pais ${ }^{33}$.

Tomando en cuenta estas deficiencias, y los criterios ya expuestos para corregirlas o aminorarlas, se construyó una serie de las importaciones mexicanas por países entre 1870 y 1892 con base en las cifras de los socios comerciales de México. Las estadísticas alemanas (comercio especial) se utilizaron sin operar en ellas ajuste alguno, salvo la conversión a dólares y años fiscales, pero sólo se dispuso de ellas a partir de $1890^{34}$. La participación conjunta de los socios principales en el comercio de importación mexicano se estimó a partir de las fuentes MX disponibles. En promedio, se calculó su aportación en el 78 por 100 del total cuando faltaban los datos de Alemania y en el 88 por 100 cuando se disponía de ellos ${ }^{35}$. Al comercio proveniente de estos cuatro países se añadió el que se originaba en España y Bélgica de acuerdo con las estadísticas $\mathrm{MX}$, siempre que éstas se encontraron disponibles ${ }^{36}$. A partir de esas proporciones se estimó el valor anual f.o.b. de las importaciones de mercancías en dólares. Los resultados se ilustran en el gráfico 2 (al final de esta sección, p. 231) y se reproducen en el cuadro 2 (al final de la última sección, pp. 249-251).

\section{B) «Mucha administración», estadísticas confiables: 1892-1912}

En varios sentidos puede decirse que hacia principios de los años 1890 la administración porfirista alcanzó su madurez, lo cual condujo al inicio de la era estadística en México. Como resultado de ello, no sólo se dispone de una información cuantitativa más vasta, sino que ésta fue publicada de manera regular y conforme a criterios más uniformes. La calidad y consistencia de los datos oficiales (observable en el gráfico 1) permitió utilizarlos como base para rectificar las series del comercio bilateral con los principales socios y obtener series completas con un alto grado de com-

${ }^{33}$ El procedimiento se explica con mayor detalle en Kuntz Ficker (2001).

${ }^{34}$ Existen cifras no oficiales del comercio de Alemania con México y Centroamérica para los años anteriores a 1890 , pero éstas parecen estar muy subestimadas y no se utilizan aquí. Véase United States Treasury Department (1889), p. 263.

${ }^{35}$ De acuerdo con las estadísticas MX, Alemania tuvo una participación muy constante en las importaciones mexicanas hasta antes de la Primera Guerra Mundial; promediando un 10 por 100 del total entre 1870 y 1910 .

${ }^{36}$ Siguiendo las fuentes MX, la participación de estos dos países se estimó en alrededor del 6 por 100 del total. 
parabilidad $^{37}$. Tras realizar los ajustes necesarios, el 85 por 100 de las observaciones exhibió márgenes de discrepancia por debajo de \pm 10 por $100^{38}$. Las discrepancias que todavía superaron este margen se debieron a dos factores principales: a) el subregistro de las exportaciones EU a México, que persistió hasta 1895 , y b) las deficiencias ya mencionadas en los criterios de compilación de las estadísticas FR, que fueron sólo en parte contrarrestadas con la inclusión de algunos rubros del comercio general en la cuenta del comercio especial.

En suma, los ajustes realizados permitieron corroborar la consistencia y precisión de las estadísticas mexicanas durante esta etapa ${ }^{39}$. Por esta razón, y debido a la posibilidad de hacer uso de estas fuentes para un estudio más profundo de las pautas del comercio a lo largo de estas dos décadas, se optó por utilizar las series MX por países (rectificadas conforme a los criterios expuestos) para construir la serie del valor de las importaciones entre 1892 y $1912^{40}$. Los resultados pueden observarse en el gráfico 2 y en el cuadro 2 .

\section{C) Revolución y reconstrucción: 1913-1929}

La última etapa presenta un nuevo conjunto de dificultades. En primer lugar, entre 1913 y 1921 la continuidad y calidad de las estadísticas mexicanas se vieron severamente afectadas por la guerra civil y la inestabilidad

${ }^{37}$ Las series se uniformaron conforme a los siguientes criterios: a) todas las cifras se convirtieron a dólares de acuerdo con las tasas de cambio incluidas en el apéndice; b) a los valores oficiales $\mathrm{MX}$ se restó el de las importaciones de metálico según las estadísticas EU y GB para obtener series del comercio de mercancías; $c$ ) las series de los socios comerciales se utilizaron como sigue: para $\mathrm{EU}$ y GB, exportaciones netas; para FR, comercio especial + algodón, lana y joyería; para DT, comercio especial.

${ }^{38}$ El coeficiente de correlación de las series resultantes del comercio bilateral de los cuatro países con México es de 0,993 , con $\mathrm{R}^{2}=0,986$.

39 Una indagación realizada por la Comisión Monetaria a principios del siglo xx para evaluar las estadísticas mexicanas a partir de 1892 condujo a la conclusión de que, en la medida en que los aranceles no dependian del valor de las mercancías importadas, no había razón para subestimarlo en las declaraciones de los importadores. En consecuencia, las fuentes oficiales reflejaban con bastante precisión el valor f.o.b. de las importaciones. Comisión Monetaria (1904), p. 146.

40 Para efectuar la reconstrucción se utilizaron series por países, en las que se atribuyó un porcentaje de entre el 93 y el 96 por 100 a los cuatro socios principales más España y Bélgica. Debido a ello y a que se descontaron las importaciones de metálico conforme a las fuentes de los socios, los resultados de la reconstrucción no son idénticos a los que ofrecen las fuentes MX. La diferencia, sin embargo, se encuentra por debajo del 2 por 100 en todos los casos. 
subsecuente. Como resultado, las cifras disponibles denotan cierto nivel de subregistro debido al escaso control sobre los flujos del comercio en algunos años y a la aplicación de criterios deficientes de compilación en otros. Para empeorar las cosas, las fuentes de los socios europeos se vieron también en mayor o menor medida afectadas por la guerra mundial, por lo que una simple sustitución de los valores faltantes en las fuentes MX no siempre es practicable. Con todo, hay muchos más datos del lado de los socios que de parte de México: aunque no se dispone de datos DT entre 1914 y 1924, las estadísticas FR y GB están completas. Por otro lado, es sabido que durante los años de la guerra mundial los países europeos redujeron drásticamente su comercio con México, en tanto este país concentraba una parte sustancial de sus intercambios con el exterior en los Estados Unidos (que aportaron en promedio el 77 por $100 \mathrm{del}$ comercio de importación entre 1913 y 1929). Afortunadamente, los datos EU son completos y bastante confiables para este período.

Otras dificultades se refieren a los sistemas de compilación y clasificación empleados por México y sus socios comerciales. Mientras que estos últimos adoptaron la Nomenclatura Internacional de Bruselas a principios de los años 1920, México sólo se adhirió plenamente a la clasificación internacional en $1929^{41}$. Otros cambios en los criterios de compilación afectaron la comparabilidad de las series mexicanas en ese decenio. Por ejemplo, las cifras MX y FR se comparan mucho mejor si se considera el comercio general de Francia en vez del comercio especial. Una fuente más de confusión se origina en el hecho de que las fuentes mexicanas siguieron utilizando una tasa legal fija a la par del dólar (1:0,4984) durante los años 1910, pero en la década siguiente las fuentes no refieren el tipo de cambio empleado en el registro de las importaciones. A partir de 1925

${ }^{41}$ La Nomenclatura Internacional se diseñó en la Convención de Bruselas en 1913, pero su adopción fue retardada por el estallido de la Primera Guerra Mundial. Al término de la guerra la Liga de Naciones promovió su empleo, que se difundió durante los años veinte. El sistema de Bruselas estableció una agrupación conforme al uso final de los productos (animales, alimentos y bebidas, materias primas, manufacturas y oro y plata). En México se empleaba una clasificación conforme a la composición material y el origen sectorial de los productos (animales, vegetales, minerales, textiles, químicos, bebidas, papel, máquinas, vehículos, armas). Las autoridades se resistían a adoptar la nomenclatura de Bruselas porque la consideraban inadecuada para «las necesidades estadísticas de nuestro país». Sin embargo, a fines de los años veinte cedieron ante «la ventaja "que ofrece la comparabilidad entre sí de las estadísticas mundiales del comercio exterior». Un resumen del comercio mexicano entre 1925 y 1929 utilizando la clasificación de Bruselas se publicó en Departamento de la Estadística Nacional (1932), p. 444, y cifras desglosadas para 1927 y 1928 se incluyeron en Departamento... (1930), passim. Ver Allen y Ely (1953), pp. 242-245; League of Nations (1927-1928), passim; Departamento... (1932), p. 442. 
la comparabilidad de los datos mexicanos empeora considerablemente si se aplica la tasa legal, por lo cual he asumido que ésta fue remplazada en la práctica por la tasa de cambio de mercado. Finalmente, a partir de 1921 las fuentes EU no distinguen el comercio neto del total, por lo que aquél fue estimado, conforme a las tendencias observadas, en el 97 por 100 de sus exportaciones totales a México.

En suma, las características de las fuentes obligaron en esta tercera etapa a un compromiso: la reconstrucción de las series está basada en las fuentes de los socios comerciales, pero en los casos en que se carecía de ellas o en que las disponibles eran muy deficientes, se hizo uso de las fuentes MX para cubrir las brechas en la información ${ }^{42}$. Las nuevas series utilizan exportaciones netas de EU y GB, comercio especial en el caso de Alemania y comercio general en el caso de Francia. Cuando se dispuso de datos para todos los socios (incluidos España y Bélgica según las fuentes $\mathrm{MX}$ ), se les asignó una participación que varió entre el 93 y el 99 por 100 para estimar el valor total de las importaciones durante estos años.

La nueva serie de importaciones de mercancías entre 1870 y 1929 se ilustra en el gráfico 2 . A ella se ha agregado, con propósitos de comparación, la serie de los valores oficiales de las importaciones totales de acuerdo con las fuentes MX disponibles para todo el período.

La serie designada como «mercancías SK-Sandra Kuntz» representa mi propuesta de reconstrucción de los valores anuales de las importaciones de mercancías entre 1870 y 1929 . Es innecesario aclarar que esta serie está sujeta a ajustes posteriores y puede volverse más precisa a medida que mejore nuestro conocimiento de las rutas y patrones del comercio, o cuando se disponga de información cuantitativa nueva o más confiable. En tanto ello sucede, esta serie es la más completa de que se dispone, y la primera que ha sido construida con criterios explícitos y susceptibles de verificación.

Aunque el análisis de las tendencias del comercio cae fuera del alcance de este trabajo, valgan algunos comentarios para destacar la importancia y la periodización del proceso de apertura que estaba teniendo lugar. En primer lugar, las modestas dimensiones del comercio de importación en la década de 1870 se asocian a una economía tradicional pequeña y que

${ }^{42}$ Se utilizaron cifras MX para las importaciones francesas en 1912, 1915, 1918, 1919 y de 1923 a 1929, y para las alemanas entre 1914-1916 y 1919-1924. Los datos DT para 1913 se obtuvieron de Zuckermann (1921), p. 133. 


\section{GRÁFICO 2}

Importaciones mexicanas, $1870-1929$

(valores nominales f.o.b.)

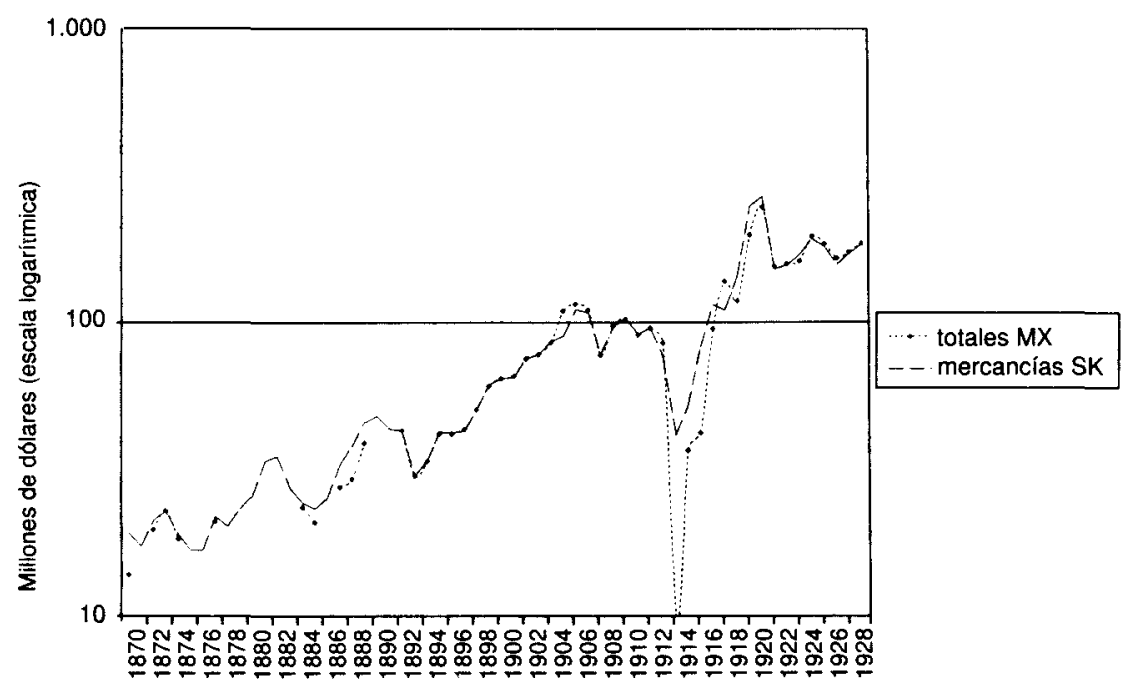

1870-1917: año fiscal; después, año natural

MX: Elaborada a partir de las estadisticas oficiales de México.

SK: Elaboración a partir de las fuentes oficiales de México y de sus principales socios comerciales. Para fuentes véase bibliografía.

posee escasos lazos con el mercado internacional ${ }^{43}$. Aunque esta situación empezó a modificarse en el siguiente decenio, fue en 1893 cuando se inició la primera aceleración en el crecimiento de las importaciones que habría de prolongarse por más de una década. El auge se extendió por un lapso de quince años, en que las importaciones crecieron a una tasa anual de más del 10 por 100 , pero se vio frenado por el impacto de la crisis de 1907, y más severamente afectado por la generalización de la guerra civil en 1914. Aunque importante, el descenso producido por la guerra civil fue mucho menor al consignado en las fuentes oficiales, y fue seguido

${ }^{43} \mathrm{El}$ comercio exterior de México antes de $1880^{\circ}$ no era distinto al de otras economías preindustriales: "Antes de la revolución industrial, el comercio consistía mayormente en un intercambio más bien especulativo y poco sistemático de excedentes por bienes suntuarios». William R. Leonard, «International Comparisons and Standardization», en Allen y Ely (1953), p. 240. 
de una rápida recuperación a fines de los años 1910 e inicios de los 1920 . Después de dos años de valores excepcionalmente altos, las importaciones retornaron a un comportamiento más ordinario, aunque en una escala superior, a partir de 1922. La tasa de crecimiento de las importaciones mexicanas promedió un 4 por 100 anual para todo el período. Este ritmo muy aceptable refleja la transición de una economía cerrada a otra relativamente abierta e integrada al sistema mundial. Las importaciones per capita aumentaron de 2 dólares en 1870 a 11 dólares en $1929^{44}$. Desde la perspectiva de México éste fue un progreso importante, aunque el resultado parece aún modesto si se le compara con otros países latinoamericanos.

\section{LAS EXPORTACIONES}

La reconstrucción de las series anuales de exportación presenta un tipo distinto y acaso más complejo de dificultades. Aunque el recuento estadístico de estos movimientos se inició más tempranamente y su publicación exhibe mucha mayor continuidad, criterios de compilación peculiares y otras deficiencias hacen que las cifras oficiales $M X$ sean menos susceptibles de comparación. El primer y más serio inconveniente es que estas fuentes no distinguen entre comercio de mercancías y flujos de dinero en especie o metálico (specie), sino entre «metales preciosos» y «demás artículos». Aunque el rubro de metales preciosos incluye oro y plata en lingotes y moneda, abarca también piedra mineral, concentrados y mezclas (con cobre, plomo y cinc), sulfuros y cianuros, es decir, un conjunto de productos que de ninguna forma debieran confundirse con los flujos de metálico. El peso de estos productos minerales en las exportaciones fue insignificante en los primeros años del período, cuando la industria minera del país se especializaba en la producción de metales preciosos y la ley prescribía que todos los minerales de oro y plata extraídos de las minas se acuñaran. Sin embargo, su importancia creció a medida que la industria minera se diversificó y que las restricciones para la exportación de minerales y metales empezaron a relajarse ${ }^{45}$. En 1903 solamente el 40 por 100 del valor de las exportaciones realizadas bajo el rubro de «metales preciosos» consistía en monedas y lingotes de oro y plata, en tanto el resto se componía de todos los otros productos minerales mencionados.

4 Para los principales indicadores de la evolución del comercio ver cuadro 1 en la última sección (p. 246).

45 Acerca de las regulaciones en torno a la exportación de metales ver Riguzzi (2000). 
La compilación de estadísticas comerciales publicada por El Colegio de México agrava de hecho este problema, porque, además de reproducir el mismo criterio de las fuentes oficiales, presenta bajo el rubro de «metales preciosos» no sólo el valor de las exportaciones, sino el de la producción nacional de esos artículos ${ }^{46}$. Aparentemente la intención fue calcular la capacidad total para importar derivada de la producción de metales preciosos y de las exportaciones de los «demás artículos» ${ }^{47}$. Sin embargo, el resultado es que esta compilación es de escasa utilidad para conocer ya sea el valor de las exportaciones de mercancías (que debería incluir todos los productos mineros que no fueran lingotes y moneda) o el valor total de las exportaciones (que de ninguna manera debería incluir la producción total de metales preciosos). Resulta claro que estos procedimientos disminuyen también la utilidad de las estadisticas cuando se trata de comparar y corroborar las cifras mexicanas en el plano internacional. Al mismo tiempo, dificultan severamente las estimaciones de la balanza del comercio, aunque sólo sea porque todas las exportaciones mexicanas (incluidos los flujos de metálico) son en última instancia contabilizadas como comercio de mercancías ${ }^{48}$.

La importancia de distinguir el comercio de mercancías de las transferencias de dinero en especie deriva no sólo de la necesidad de hacer comparables las estadísticas mexicanas en el plano internacional, sino también del hecho, generalmente ignorado en la literatura sobre el tema, de que una parte de estas transferencias no representaba un intercambio de mercancías de México con el resto del mundo. En cambio, muchas de ellas formaban parte de la cuenta corriente de la balanza de pagos, y algunas se inscribían en la cuenta de capital ${ }^{49}$. Las salidas de oro y plata en metálico sirvieron en muchos años para saldar el déficit en la balanza comercial

46 El Colegio de México (1960), p. 75.

47 El Colegio de México (1960), p. 12.

48 El Colegio de México (1960), p. 175.

49 En general, los socios comerciales de México distinguían entre comercio de mercancías y flujos de metálico en su recuento del comercio exterior. En el caso de Estados Unidos las dos fuentes más utilizadas siguieron esta pauta hasta 1894, año en el cual el Statistical Abstract adoptó el mismo criterio de las fuentes MX, pero el Foreign Commerce and Navigation siguió desglosando las exportaciones de metales preciosos para distinguir entre sus varios componentes. En opinión del cónsul norteamericano en México, las estadísticas mexicanas de exportación provocan equívocos «cuando se les compara con las estadísticas comerciales del Reino Unido, Francia, Alemania y los Estados Unidos, de cuyas estadísticas comerciales oficiales se excluyen los metales preciosos, que se incluyen en sus cuentas en forma separada y nunca incluidos con la mercancía que compone el comercio regular». US Department of Commerce... (1906), p. 17. 
y para pagar los intereses y dividendos de las empresas extranjeras que operaban en el país, así como también para el pago de deudas en el exterior y para la formación de saldos en bancos extranjeros en épocas de devaluación. La simple agregación de todas las exportaciones en la cuenta comercial impide seguir el desenvolvimiento del sector exportador y la evolución de la posición internacional de México, e impide, por supuesto, cualquier acercamiento a la reconstrucción de la balanza de pagos a lo largo del período.

Sin embargo, existe cierta dificultad para decidir cuándo las exportaciones de oro y plata en lingotes y moneda representaban tráfico de mercancías y cuándo constituían transferencias de dinero. En términos generales, el criterio decisivo refiere a las necesidades de la oferta monetaria dentro del país en cuestión: en la medida en que el metálico exportado se sustrae de la circulación monetaria interna (provocando escasez de dinero $\mathrm{y}$, entonces, cambios en el nivel de precios) debe considerarse una transferencia de dinero en especie ${ }^{50}$. En el caso de un país productor de metálico el problema es más complejo, puesto que remite a la capacidad de absorción de circulante por parte de la economía. En este sentido, las exportaciones mexicanas de oro y plata en barras y moneda serían transferencias de metálico en la medida en que afectaran la oferta monetaria interna o mantuvieran el crecimiento de ésta por debajo de las necesidades de una economía en expansión. Diversos testimonios de la época hablan, en efecto, de una escasez monetaria provocada por las transferencias de metálico al exterior. Véanse, por ejemplo, los siguientes, extraídos de reportes consulares estadounidenses elaborados en 1890 y 1903 :

Como las exportaciones de metal blanco se incrementaron, se ha notado una marcada escasez de dólares del águila en México, y sólo la más firme y conservadora acción de parte de los principales bancos, ayudados de manera eficiente aunque no activa por el Gobierno, evitó una hambruna de dinero y un pánico financiero. Probablemente la oferta visible de metal blanco en todas sus formas fue menor en octubre 15 de 1890 que en ninguna otra fecha durante los pasados diez años ${ }^{51}$. México tiene escasez de moneda de plata el día de hoy, cualquiera que pueda ser la causa -incremento de la demanda oriental, más amplio uso doméstico, o ambas causas y otras-. Los bancos no tienen suficiente dinero para enfrentar las demandas de los negocios, que cada día se apiñan con más fuerza sobre ellos [...] Éstas no son, de manera general, más que evidencias adicionales del aumento en la actividad empresarial, y son buenos augurios. Pero también apuntan a una

${ }^{50}$ Lancaster (1977), p. 928.

"US Department of State (1890), p. 542. 
cierta astringencia en el mercado mexicano de dinero en el momento actual $[\ldots]^{52}$.

Ello significa que un monto indeterminado de dinero era efectivamente extraído de la circulación monetaria interna para enviarse al extranjero. Éste es el monto que debiera considerarse como metálico; por encima de él, las exportaciones de lingotes y moneda caerían, en sentido estricto, bajo la definición de mercancías ${ }^{53}$. Sin embargo, para aplicar este criterio sería necesario disponer de los elementos que nos permitieran estimar las necesidades de la circulación monetaria interna y compararlas con la oferta efectiva en cada año ${ }^{54}$. A falta de estos elementos, es preciso adoptar otro criterio, menos preciso pero por lo pronto el único asequible: el de la función intrínseca de los metales como medios de pago. México fue a lo largo del período un gran productor de plata $-\mathrm{y}$ a partir de finales de siglo también de oro-, y mantuvo hasta 1905 un patrón bimetálico en teoría pero en realidad basado en la plata. En ese año se adoptó un patrón de cambio oro, lo que significó suspender la libre acunación de la plata y prohibir la reimportación de sus cuños. Sin embargo, resulta evidente que ello no implicó el abandono del uso monetario de la plata ni el cese inmediato de su circulación. De hecho, debido a las circunstancias impuestas por la guerra civil, a partir de 1914 se volvió a extender el uso de la moneda de plata, y el gobierno siguió acuñándola en montos importantes hasta $1927^{55}$. A partir de las consideraciones anteriores, en este trabajo se han adoptado provisionalmente los siguientes criterios: $a$ ) las exportaciones de oro en lingotes y moneda se consideran como metálico

52 US Department of Commerce... (1904), pp. 128-129.

53 Luis Cerdá coincide con este criterio, al menos por lo que respecta a la exportación de monedas de oro y plata. Considera que las exportaciones de moneda limitaron las reservas en poder del sistema bancario, por lo que el aumento de la oferta monetaria que la actividad económica demandaba debió basarse en moneda fiduciaria no respaldada por metálico. Ver Cerdá (1992), p. 16, y (1991), p. 326. Una interpretación opuesta, para la cual las exportaciones de pesos de plata formaban parte del comercio de mercancías, se encuentra en Schell (1996), p. 72. Otro autor acepta que las exportaciones de plata se utilizaban en parte para pagar intereses y dividendos de las inversiones extranjeras y provocaban, en efecto, escasez de numerario dentro del país, pese a lo cual las considera parte del comercio de mercancías. Ver Torres Gaytán (1990), pp. 44, 51, 65.

54 Por lo pronto sólo disponemos de las estimaciones de Cerdá acerca del incremento de la oferta monetaria en el largo plazo. De acuerdo con sus datos, entre 1882 y 1900 el crecimiento de la moneda en metálico fue del 3,5 por 100 anual, en tanto la moneda fiduciaria creció anualmente un 21,5 por 100 en promedio. Ver Cerdá (1992), p. 16, y (1991), p. 326.

"Torres Gaytán (1990), cuadros en pp. 145 y 166. 
a lo largo de todo el período; $b$ ) las exportaciones de monedas de plata se incluyen también en los movimientos de metálico, debido a que se sustrajeron al flujo monetario doméstico ${ }^{56}$; $c$ ) por último, las exportaciones de lingotes de plata se consideran transferencias de metálico hasta 1905, pero a partir de este año se les suma al tráfico de mercancías debido a que la reforma monetaria prohibió su libre acuñación ${ }^{57}$.

Para reconstruir el valor anual de las exportaciones conforme a estos criterios fue necesario reagrupar los rubros originales de las fuentes mexicanas para producir nuevas series que distingan entre exportaciones de mercancías y flujos de metálico. Para ello se utilizaron las estadísticas de exportación por producto, o aquellas que desglosan el rubro de «metales preciosos» en sus distintos componentes. Cuando no se dispuso de esta información (lo cual sucedió en diez de sesenta años), la reconstrucción tuvo que basarse enteramente en las cifras que aportan los socios principales, cuya consistencia fue puesta a prueba a partir de la comparación con las fuentes MX disponibles.

Otro tipo de dificultades se relaciona con los criterios de valoración empleados en las estadísticas de cada país. En el caso de México, la distorsión más notoria radica en que hasta 1905 el oro y la plata exportados en cualquiera de sus formas se valuaron a una tasa legal fija impuesta por el gobierno que no necesariamente coincidía con el precio de mercado de estos metales. Como el precio internacional de la plata se devaluó severamente a partir de los años setenta, el valor anual de las exportaciones de ese metal aparece inflado en las estadísticas mexicanas, en tanto el del oro acusa una subestimación a partir de 1894. Para hacer utilizables las cifras mexicanas, las

${ }^{56}$ Podría pensarse que la moneda de plata que se exportó después de la reforma monetaria lo hizo como mercancía, puesto que el gobierno prohibió su reimportación. Este supuesto sólo afectaría las series de exportación en tres años en que las salidas de moneda de plata fueron significativas: 1906 (con 12,6 millones de dólares), 1907 (con 5,6 millones) y 1912 (con 4,8 millones de dólares). Salvo en estos tres años, entre 1906 y 1929 las salidas de moneda argéntea fueron poco importantes, rebasando apenas cuatro millones de dólares en veintiún años de acuerdo a las fuentes $M X$. Si se atiende a las estadísticas EU, sin embargo, estas transferencias habrían tenido cierta importancia entre 1917 y 1921, con un promedio de tres millones de dólares en cada uno de esos años.

57 Es probable que las series así obtenidas deban rectificarse a partir de cálculos más finos una vez que se haya resuelto la cuestión analítica central, y que se disponga de información suficiente para analizar las distintas variables que influyeron sobre la oferta monetaria a lo largo del período. A partir del criterio propuesto se obtendrán valores máximos de los flujos de metálico al exterior, que tienen, no obstante, la ventaja de ofrecer órdenes de magnitud, de los cuales puede descontarse el monto que exceda a las necesidades de la circulación monetaria interna. 
exportaciones de oro y plata se convirtieron a su valor comercial, lo cual mejoró significativamente la comparabilidad de las series $\mathrm{MX}^{58}$. El sistema de valoración adoptado por los distintos socios involucrados en el comercio con México también provoca discrepancias en la comparación de las diversas series. La razón es que mientras las fuentes $\mathrm{MX}$ y EU utilizan valores f.o.b., las estadísticas de GB, FR y DT capturan el valor c.i.f. de sus importaciones 59 . Para hacer comparables las estadísticas de los socios europeos es preciso descontar el costo del transporte y otros invisibles con el fin de uniformar todas las series reduciéndolas a valores f.o.b. La estimación de estos costos es un ejercicio complejo que rebasa los propósitos de este artículo. Por el momento, a partir de algunas estimaciones disponibles se asume aquí que los costos invisibles de las exportaciones mexicanas de mercancías hacia Europa representaron el 15 por 100 de su valor c.i.f. hasta 1890 , y el 10 por 100 a partir de entonces ${ }^{60}$. Este porcentaje se descontó de las cifras c.i.f. provistas por cada uno de los socios europeos antes de compararlas con los valores f.o.b. de las exportaciones según las fuentes MX. Finalmente, el valor MX de las exportaciones fue registrado originalmente en pesos (en vez de la tasa legal usualmente adoptada para las importaciones). Los valores oficiales $\mathrm{MX}$ se han convertido a dólares a la tasa de cambio de mercado, al igual que los de cada uno de los socios comerciales de México (para los tipos de cambio utilizados, véase apéndice, p. 260).

Debido a las deficiencias que presentan las cifras MX del comercio de exportación, las series anuales de las exportaciones de mercancías dirigidas a cada uno de los principales socios europeos se han basado preferentemente en las estadísticas que ofrecen estos últimos. La reconstrucción de las exportaciones a Estados Unidos mereció un tratamiento distinto,

${ }^{58}$ Para ello fue necesario hacer uso de las cantidades de oro y plata contenidas en las exportaciones de minerales, mezclas, lingotes y moneda y multiplicarlas por el precio internacional de ambos metales. Este último se obtuvo de Statistical Abstract, núms. 32 (1910), 42 (1920), 48 (1926) y 52 (1930).

59 C.i.f. = cost insurance freight, lo que significa que se incluye el costo del transporte y el seguro. Por otra parte, mientras que las fuentes EU y GB utilizan valores declarados de las importaciones, FR y DT emplean valores oficiales hasta 1920, revisados anualmente a partir de 1901. Las estadísticas MX recogen valores declarados, excepto para el oro y la plata, que, como se explicó ya, se valuaron a una tasa legal. Allen y Ely (1953), pp. 87, 94, 300, 370. Asimismo, League of Nations (1928), pp. 22-23.

${ }^{60} \mathrm{La}$ Comisión Monetaria calculó el costo de transporte y seguros de las importaciones mexicanas en el 15 por 100 de su valor. Por otra parte, Simon ha calculado el costo promedio del transporte de las exportaciones de Estados Unidos entre el 14 y el 7 por 100 de su valor para el período 1870 a 1900 . Se puede presumir que las exportaciones desde México impusieron costos ligeramente superiores a éstos a lo largo del periodo. Comisión Monetaria (1904), p. 146; Simon (1960), p. 650. 
debido a la importancia que adquirió el comercio bilateral y a la progresiva concentración de las exportaciones mexicanas en ese país a lo largo del período. En este caso se utilizaron las fuentes oficiales de ambas procedencias para probar la confiabilidad y comparabilidad de las series, y se reagruparon los valores del comercio total para distinguir entre intercambio de mercancías y flujos de metálico. Las series finales de las exportaciones mexicanas a Estados Unidos constituyen una combinación de las dos fuentes disponibles en la que se rectifican las distorsiones observadas en cada una de ellas y se obtienen valores que probablemente reflejan con mayor fidelidad los flujos reales ${ }^{61}$.

De esta forma, se obtuvieron series de las exportaciones de mercancías a cada uno de los destinos principales. Al valor agregado de las exportaciones dirigidas a los cuatro socios se otorgó una participación de entre el 91 y el 98 por 100 del total hasta 1923 y del 83 al 89 por 100 a partir de entonces, conforme a las proporciones observadas en las fuentes MX disponibles ${ }^{62}$. Con estas proporciones se reconstruyó el valor anual de las exportaciones mexicanas de mercancías, que se ilustra en el gráfico 3 (serie «mercancías SK») y se reproduce en el cuadro 2 (pp. 249-251). Con propósitos de comparación, el gráfico incluye también la serie de las exportaciones de «demás artículos» de acuerdo a las fuentes oficiales MX.

En cuanto a los flujos de dinero en especie, se construyó una nueva serie de los valores totales utilizando las fuentes de los principales destinatarios (EU y GB) para completar y rectificar las cifras $\mathrm{MX}$ disponibles. Estas últimas fueron depuradas para excluir los minerales y metales que no eran metálico, y fueron convertidas a su valor comercial en dólares. Las series anuales de las transferencias de metálico y de las exportaciones totales se presentan en el gráfico 4, que incluye tanto los valores oficiales de acuerde a las fuentes MX como los resultantes de la reconstrucción.

Los gráficos 3 y 4 permiten apreciar dos discrepancias fundamentales entre las series oficiales MX y las series SK que propone esta reconstrucción. La primera consiste en la persistente subestimación de las exportaciones de mercancías en las fuentes $\mathrm{MX}$ que comprende prácticamente todo el

${ }^{61}$ Los criterios para la reconstrucción del comercio bilateral México-Estados Unidos se exponen con mayor detalle en Kuntz Ficker (2001), passim.

${ }^{62}$ Al igual que en el caso de las importaciones, se dispone de pocas cifras para el comercio con Alemania antes de 1890 y después de 1913. En los años faltantes se estimó su participación en el total conforme a las fuentes $\mathrm{MX}$, y se sumó este porcentaje al agregado a partir del cual se estimaron los valores totales. 


\section{GRÁFICO 3}

Exportaciones mexicanas de mercancias, 1870-1929

(valores nominales f.o.b.)

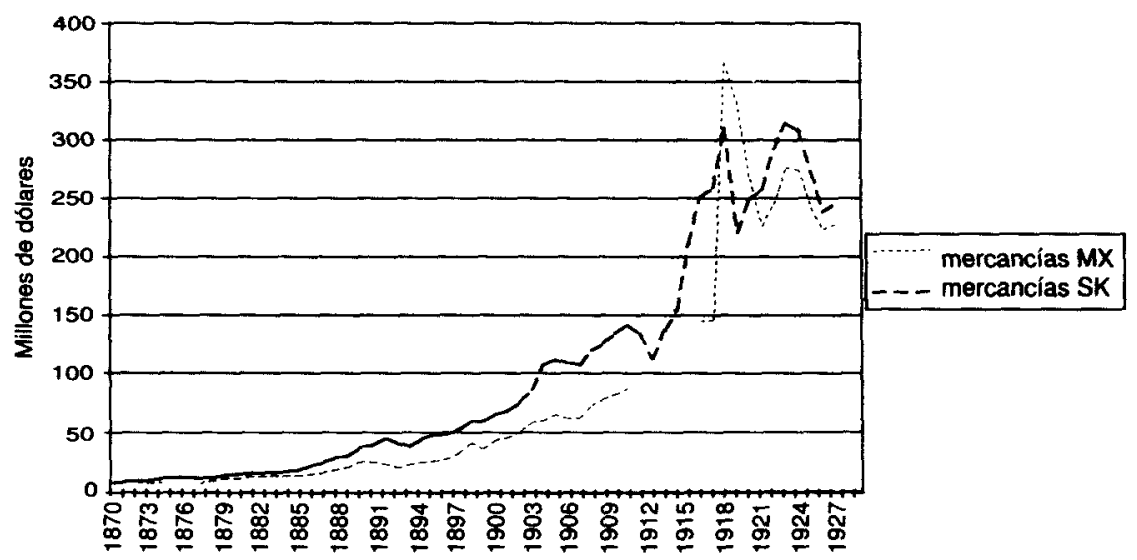

1870-1917: año fiscal; después, ano natural

período (gráfico 3) ${ }^{63}$. La mayor parte de esta subestimación debe atribuirse al criterio por el cual una parte de las exportaciones de minerales se excluía del comercio de mercancías y se atribuía al de metales preciosos. Pero cierto grado de discrepancia persiste incluso si se comparan los valores totales de las exportaciones (mercancías más metálico, designados como «totales» en el gráfico 4). Ello sugiere que antes de la revolución las estadísticas mexicanas se vieron afectadas también por el subregistro, que en algunos años pudo deberse al contrabando (sobre todo en el caso de las exportaciones gravadas) y en otros a problemas de valoración. Analistas de la época consideran que los valores de algunas de las principales exportaciones, tal como fueron registrados por el gobierno, fueron subestimados en los años anteriores a la revolución y sobrestimados en la década de

${ }^{63}$ Con excepción de los años 1920 a 1922, en que las cifras MX son superiores a las de la reconstrucción, debido, en mi opinión, a una severa sobrestimación de las primeras que las hace poco confiables. De hecho, en estos años existen cifras contrastantes dentro de las propias fuentes mexicanas. Aquí se han utilizado las que proceden de la única fuente que contiene datos completos [Departamento... (1923?)], pero otra fuente de la misma procedencia registra cifras mucho menores (y probablemente más precisas) del comercio con Estados Unidos [Departamento (1924), p. 63]. 


\section{GRÁFICO 4}

Exportaciones mexicanas de metálico y totales, 1870-1929

(valores nominales f.o.b.)

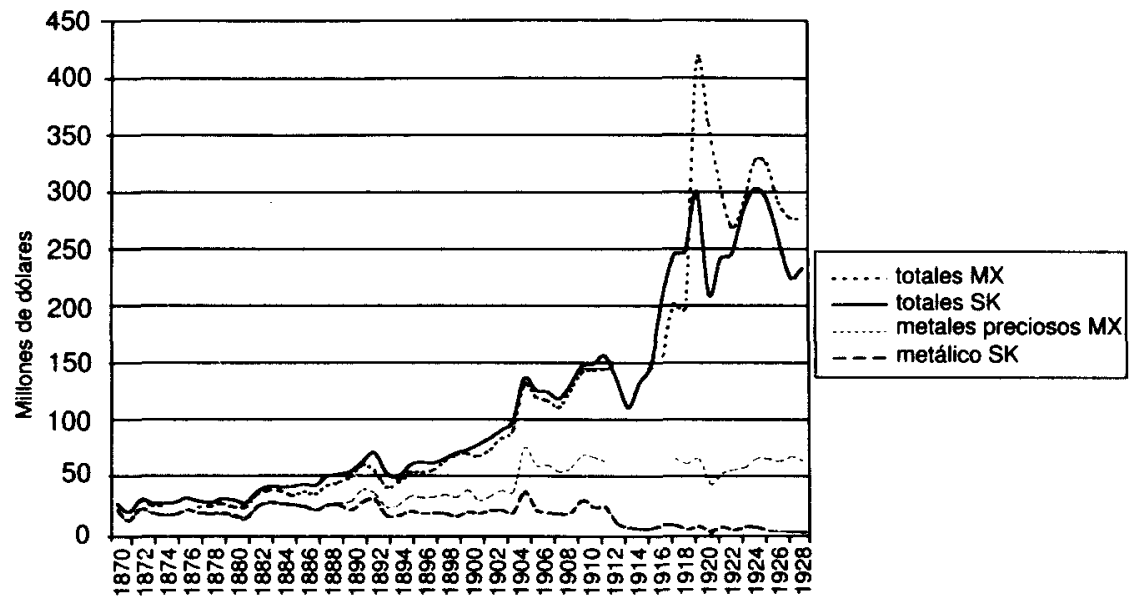

1870-1917: ano fiscal; despues, año natural

MX: Elaborada a partir de las estadísticas oficiales de México

SK: Elaboración a partir de las fuentes oficiales de México y de sus principales socios comerciales. Para fuentes véase bibliografia.

$1920^{64}$. Esto explicaría en parte el que las cifras MX sean superiores a las de la reconstrucción en la última década del período.

El segundo ámbito de discrepancia se observa en las exportaciones de metálico («metales preciosos» en el caso de MX), ilustradas en el gráfico 4. Las fuentes mexicanas registran valores consistentemente superiores a partir de los años noventa debido a la inclusión de productos minerales que no erari dinero en especie. La consecuencia de ello es ocultar el monto de metálico transferido al exterior para el pago de importaciones, deudas, intereses y dividendos, así como la dinámica de esas transferencias a lo largo del tiempo. Lo que las cifras MX indican es una tendencia al incremento progresivo de las exportaciones de metales preciosos entre 1870

${ }^{64}$ Ver Sherwell (1929), pp. 30-32. El autor refiere «una discrepancia entre los valores de mercado y los valores oficiales dados por el gobierno mexicaro» a diversos productos agrícolas y minerales, y continúa: «En 1910 había una clara subvaluación, mientras que en 1926 ocurría lo contrario». Sherwell no explica, sin embargo, las razones de esa discrepancia. 
y 1918 (su valor en dólares pasó de 21 millones en el primer año a 67 millones en el último) y una estabilización en la última década. La nueva serie (metálico SK) muestra, en cambio, que los movimientos de metálico se mantuvieron notablemente constantes entre 1870 y 1912, para disminuir progresivamente a partir de entonces ${ }^{65}$. Pero esta serie sugiere también los motivos de estas transferencias. Así, el flujo tradicional destinado a cubrir el saldo de las importaciones se vio por primera vez incrementado en la década de los ochenta por la reanudación del pago del servicio de la deuda pública externa ${ }^{66}$. En 1892 las transferencias de metálico alcanzaron un pico histórico de 32 millones de dólares como consecuencia de la crisis agrícola y económica del país, pero se redujeron a 19 millones en promedio entre 1893 y 1904, gracias al crecimiento consistente de las exportaciones de mercancías que permitió reducir el déficit en la balanza comercial. Estos flujos, entonces, representaron sobre todo remesas para el pago de deudas, intereses y dividendos a los acreedores e inversionistas extranjeros ${ }^{67}$. Un nuevo pico se alcanzó en 1905 con 50 millones de dólares, de los cuales 30 millones se utilizaron para adquirir el oro requerido para la Reforma Monetaria, tras de lo cual las exportaciones de metálico volvieron al nivel de 19 millones de dólares anuales en promedio ${ }^{68}$. El inicio de la revolución provocó una salida extraordinaria de metálico en los primeros años (unos 25 millones de dólares anuales entre 1910 y 1912), en parte por la fuga de capitales ante la inestabilidad política. Posteriormente se suspendió el servicio de la deuda pública y se redujeron sustancialmente las remesas privadas al exterior, por lo que las exportaciones de metálico cayeron por debajo de diez millones de dólares anuales a partir de 1913 (véase cuadro 2, p. 249-251).

Una vez que se asume que las transferencias de metálico no son parte del tráfico mercantil, resulta claro que para estudiar el désempeño del sector exportador es preciso concentrarse en las exportaciones de mercancías (gráfico 3 y cuadro 2). Éstas crecieron lentamente hasta 1885, y en esta fecha iniciaron una tendencia ascendente que, salvo algunos tropiezos transitorios (1893-1994, 1908), habría de prolongarse hasta 1912.

${ }^{65}$ Si se asumen los criterios propuestos aquí, las exportaciones de metálico promediaron 22,7 millones de dólares $(s=4,8)$ entre 1870 y 1912; 6,1 millones $(s=2,2)$ entre 1913 y 1920, y 2,5 millones de dólares $(s=2,2)$ en los últimos años. Para 1927, las remesas de metálico al extranjero prácticamente habían desaparecido. Para los valores anuales véase cuadro 2, columna $(f)$, pp. 249-251.

${ }^{66}$ Acerca del monto de recursos destinados al pago de la deuda ver Carmagnani (1994), apéndice 2 .

67 Torres Gaytán (1990), pp. 65, 82.

${ }^{68}$ Rosenzweig (1985), pp. 643. 
En este período de veintisiete años las ventas de mercancías al exterior crecieron a una tasa media del 8,4 por 100 por año, un desempeño sobresaliente desde cualquier punto de vista. Por otra parte, las nuevas series de exportación abren la puerta a una reconsideración del impacto de la guerra civil sobre el sector externo, pues pese a un tropiezo transitorio entre 1913 y 1915 , éste se vio favorecido tanto por la localización de los enclaves exportadores como por el auge de la demanda (y los precios) de bienes estratégicos en la coyuntura de la Primera Guerra Mundial. A la luz de las nuevas cifras, las interpretaciones que perciben un paralelismo entre la crisis revolucionaria y el desempeño de la economía mexicana deben ser matizadas en lo referente al sector exportador en varios sentidos. Por un lado, la caída de las exportaciones no fue tan profunda como las estadísticas mexicanas hacían pensar; por el otro, la recuperación fue tan rápida que hace dudar de una afectación severa a la planta productiva ${ }^{69}$.

En cambio, fue a partir de mediados de los años 1920 cuando el sector exportador mexicano empezó a perder el dinamismo que había alcanzado en el período anterior. De hecho, el valor de las exportaciones decreció en un 2,4 por 100 como promedio anual durante la década posrevolucionaria. Pese a todo, el impulso dado al sector exportador durante el porfiriato alcanzó para que, en el largo plazo, las ventas de mercancías en el exterior crecieran a una tasa del 6,2 por 100 por año entre 1870 y 1929. En términos per capita, las exportaciones de mercancías pasaron de menos de un dólar en el año inicial a 14 dólares en el final, un incremento dramático que representó una convergencia significativa con otros países latinoamericanos ${ }^{70}$.

\section{LA BALANZA COMERCIAL}

Antes de intentar reconstruir la balanza comercial de México durante estos años es conveniente dedicar algunos comentarios adicionales a las dificultades que ofrece la contabilidad de las exportaciones mexicanas de oro y plata en lingotes y moneda, pues el asunto ha sido objeto de discusión. Hemos dicho ya que en las estadísticas comerciales es frecuente separar

${ }^{69}$ Ciertamente, en ambos fenómenos influyó de manera determinante el auge de la demanda y los precios en la coyuntura de la Primera Guerra Mundial. Acerca del boom exportador de la revolución véase Kuntz Ficker (manuscrito inédito), disponible a solicitud de los interesados.

(p. 246).

${ }^{70}$ Para las tasas de crecimiento y los valores per capita de las exportaciones véase cuadro 1 
el comercio de mercancías de los movimientos de dinero en especie, que no se consideran parte del tráfico mercantil ${ }^{71}$. Sin embargo, no hay criterios definidos acerca de cómo deben computarse estos flujos en el caso de países productores de metales preciosos ${ }^{72}$. En la escasa bibliografía que existe sobre el comercio exterior de México en el siglo XIX, la práctica usual ha sido considerar todas las exportaciones de oro y plata (con amplio predominio de la última) en la misma categoría que las exportaciones de mercancías. La derivación lógica de este procedimiento ha sido concluir que la balanza comercial mexicana fue superavitaria al menos a partir de $1889^{73}$. Lo cierto es que, salvo contadas excepciones, durante la mayor parte del siglo Xxx y hasta la década de 1900 México no estuvo en condiciones de pagar por sus importaciones con la venta de mercancías en el exterior, y las transferencias de oro y plata sirvieron en parte al propósito de compensar el déficit persistente en la balanza comercial ${ }^{74}$. Otra parte se utilizó para pagar el servicio de la deuda, y otra más como intereses y dividendos de las inversiones extranjeras en el país ${ }^{75}$. En etapas de inestabilidad política o incertidumbre económica las remesas de particulares al exterior incrementaron las salidas de metálico, como sucedió claramente al inicio de la década de $1910^{76}$. En estos conceptos, las exportaciones de metálico representaron partidas invisibles de la cuenta corriente o movimientos de capital, mas no componentes de la balanza comercial.

A partir de las hipótesis que han guiado la reconstrucción y reagrupación de las series del comercio exterior mexicano, en las siguientes páginas se propone una nueva estimación de la balanza del comercio visible (gráfico 5) y otra para la balanza del comercio total (comercio visible más invisibles) (gráfico 6). Para esta última se ha considerado

${ }^{71}$ Las estadísticas británicas consideran las transacciones de metálico «como de capital (as of capital nature) y no como parte del flujo del comercio corriente de mercancías». Maizels (1952), p. 18. Para las definiciones comúnmente aceptadas ver Cohen (1969), capítulo 1.

${ }^{72}$ Foreman-Peck explica, por ejemplo: $\alpha$ El oro y la plata eran los medios últimos para resolver los desequilibrios de las exportaciones y las importaciones entre los paises, pero el oro también era una importante mercancía de exportación para Estados Unidos». Foreman-Peck (1995), p. 26.

${ }^{73}$ Rosenzweig (1985), pp. 641-642; Torres Gaytán (1990), pp. 79-80.

74 «Otro punto debe tenerse en mente al considerar el incremento aparente en favor de México en el balance del comercio: esto es, que una gran proporción de las exportaciones efectivas a los Estados Unidos en la forma de oro y plata en lingotes y moneda lo son en pago por importaciones». US Department of Commerce... (1904), p. 110.

${ }^{5}$ Cerdá (1992), pp. 15-16; Torres Gaytán (1990), p. 65.

${ }^{76}$ En sus informes al Congreso, tanto Victoriano Huerta como Venustiano Carranza se refieren a la «emigración» de gran parte de la moneda de oro y plata en los primeros años de la rev́olución. Los Presidentes (1966), pp. 91, 261. 


\section{GRÁFICO 5}

Balanza del comercio de mercancias (visible), 1870-1929

(valores nominales)

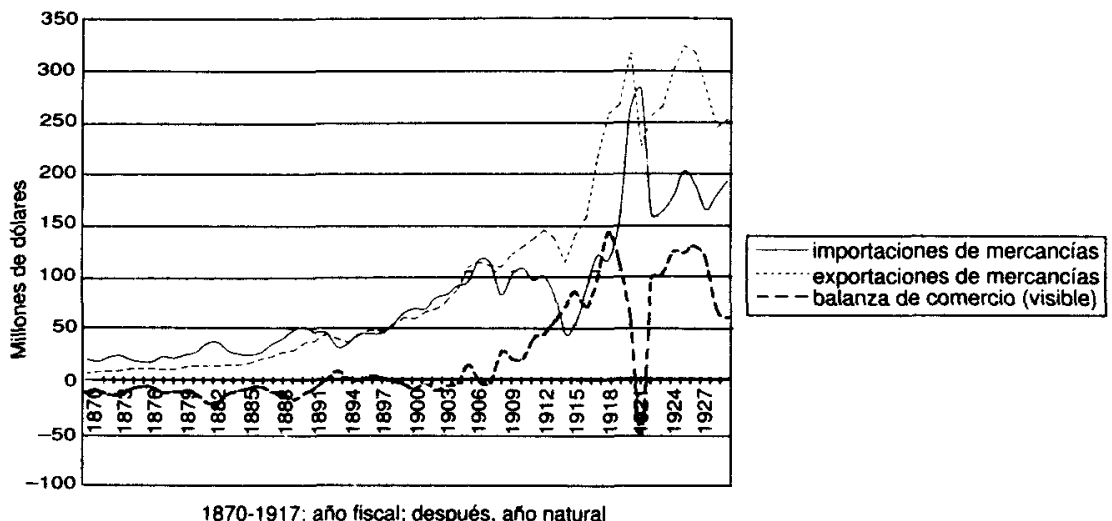

Fuentes: Estadísticas oficiales de México y de sus principales socios comerciales. Para fuentes, véase bibliografía.

\section{GRÁFICO 6}

Balanza del comercio (total) y exportaciones netas de metálico, 1870-1929 (valores nominales)

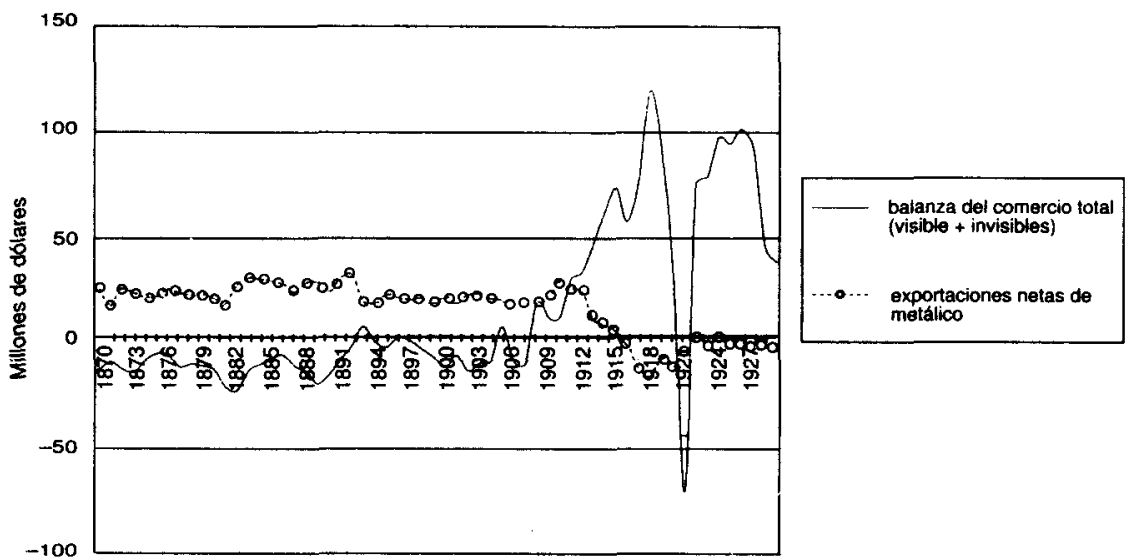

1870-1917: año fiscal; después, año natural

FuENTEs: Estadísticas oficiales de México y de sus principales socios comerciales. Para fuentes, véase bibliografía. 
el costo de transportes y seguros como una compra de servicios al exterior, y se ha estimado su valor en una proporción decreciente que representó el 15 por 100 del valor de las importaciones entre 1870 y 1884 , el 12 por 100 entre 1885 y 1890 , y el 10 por 100 a partir de entonces. Asimismo, en el gráfico 6 se ofrece una estimación de las exportaciones netas de metálico. Las series completas se reproducen en el cuadro 2 al final de esta sección.

La balanza comercial mexicana registró severos déficit en las dos primeras décadas del período. Sin contar los pagos de invisibles al exterior, el déficit promedió el 52 por 100 del valor de las importaciones en los años setenta y el 42 por 100 en la década sucesiva, pero representó el 67 y el 56 por 100 de las importaciones, respectivamente, si se considera el comercio total [para el monto anual del déficit ver columnas $(c)$ y $(e)$ del cuadro 2]. Esta situación mejoró sustancialmente a partir de la década de 1890: la balanza del comercio total arrojó un déficit promedio del 10 por 100 del valor de las importaciones en los dos decenios siguientes, y de hecho registró modestos superávit en el último lustro de 1900 . No obstante, debe tenerse en cuenta que una fracción sustancial de las importaciones se pagó con inversiones extranjeras, lo que en los hechos aligeró el peso del déficit externo. El secretario de Hacienda, Limantour, explicaba con su agudeza habitual cómo obtenía el país los recursos para pagar el saldo de su comercio y el de otros servicios obtenidos del exterior:

... [C]on respecto a la aparente insuficiencia de nuestras exportaciones para cubrir el valor de nuestras importaciones más los pagos que tienen que hacerse en el exterior por el servicio de las deudas... y el interés y dividendos de muchas empresas establecidas en este país con capital extranjero... [S]i por balanza del comercio se entiende meramente los envíos y la recepción de mercancías, no puede haber duda de que nuestra balanza es insatisfactoria, pero si se entiende la entrada y salida de valores de toda clase, incluyendo los que proporciona el uso del crédito internacional, México no debe temer... pues sin duda la inversión de capital, que fluye hacia acá desde todos lados para desarrollar los recursos naturales y crear nuevas fuentes de producción, siempre nos permitirá saldar con facilidad nuestro endeudamiento con los países extranjeros» ${ }^{77}$.

Aunque el optimismo de Limantour se toparía unos años más tarde con la avalancha revolucionaria, otros factores actuarían para producir una balanza comercial consistentemente superavitaria desde 1908 y hasta el

77 Citado en US Department of Commerce... (1905), pp. 501-502. 
final del período, con saldos favorables que rebasaron el 75 por $100 \mathrm{del}$ valor de las importaciones en la década de 1910 y se acercaron al 50 por 100 en los años de 1920. La única excepción a esta tendencia se presentó en 1921, cuando las importaciones mostraron por segundo año consecutivo máximos históricos, resultantes de la demanda de equipo y de alimentos en un año de malas cosechas, pero las exportaciones descendieron abruptamente como consecuencia de la crisis posbélica y de la caída en la demanda internacional. El cuadro 1 ofrece algunos indicadores más precisos de esta evolución.

El cuadro permite observar tanto el desempeño de largo plazo del sector externo como los ciclos por los que atravesó. El comercio exterior de México creció a ritmos aceptables en las cinco décadas de 1870 a 1919, lo cual se reflejó en un aumento significativo de los valores per capita. Contra lo que podría pensarse, este paso fue menos afectado por la contienda armada de 1910-1917 que por las circunstancias adversas de la década de 1920, entre las que se encuentran la recesión internacional de 1921, el descenso en los precios de los productos minerales y el fin del primer auge petrolero. En conjunto, estos factores generaron altibajos en el desempeño de las exportaciones, disminuyeron la capacidad para importar e iniciaron un declive que se adelantó en algunos años al colapso del comercio internacional en 1929.

Por otra parte, como se observa también en el cuadro 1, la tendencia deficitaria de la balanza comercial se revirtió gracias a un crecimiento extraordinario de las exportaciones de mercancías, siempre superior al ritmo en que se incrementaron las importaciones ( $\mathrm{y}$ a veces a más del doble de éste). Ello sugiere que el desarrollo del sector exportador se realizó en buena medida a partir de una explotación más eficiente de los recursos disponibles y que el componente importado de las exportaciones se mantuvo dentro de límites moderados. Como la importación de capitales y tecnología requeridos para el desarrollo del sector exportador no comprometió una porción abrumadora de los recursos obtenidos de la venta de mercancías en el exterior, una parte de éstos pudo haberse utilizado para la ampliación de la capacidad productiva orientada al mercado interno ${ }^{78}$. Aunque el espacio no permite por ahora ahondar en esta dimensión del proceso, las tendencias descritas

${ }^{78}$ Naturalmente, la «parte» disponible para su uso doméstico dependía del valor de retorno de las exportaciones, presumiblemente menor en sectores controlados por capital extranjero. En un artículo de reciente publicación, Edward Beatty sostiene que los ingresos crecientes derivados de las exportaciones jugaron un papel crucial en el financiamiento de un incipiente proceso de industrialización sustitutiva intensivo de bienes importados. Beatty (2000), p. 418 y passim. 


\section{CUADRO 1}

Indicadores de la evolución del comercio exterior, 1870-1929 (comercio de mercancias)

\begin{tabular}{|c|c|c|c|c|c|}
\hline \multirow[b]{2}{*}{ Períodos } & \multicolumn{2}{|c|}{ Tasas de crecimiento anual } & \multicolumn{3}{|c|}{ Valores per capita (dólares) } \\
\hline & Importaciones & Exportaciones & $A \bar{n} o s$ & Importaciones & Exportaciones \\
\hline $1870-1879 .$. & 1,8 & 6,6 & 1870 & 2,2 & 0,7 \\
\hline $1880-1889 \ldots \ldots \ldots$ & 5,9 & 7,4 & 1895 & 3,4 & 3,3 \\
\hline $1890-1899 \ldots \ldots \ldots$ & 2,5 & 5,2 & 1900 & 4,8 & 4,1 \\
\hline $1900-1909 \ldots \ldots \ldots$ & 4,0 & 7,5 & 1910 & 6,8 & 8,1 \\
\hline $1910-1919 \ldots \ldots \ldots$ & 3,4 & 7,5 & 1921 & 18,6 & 15,0 \\
\hline $1920-1929 \ldots \ldots \ldots$ & $-3,0$ & $-2,4$ & 1929 * & 11,1 & 14,4 \\
\hline $1870-1909 \ldots \ldots \ldots$ & 4,1 & 7,5 & & & \\
\hline $1910-1929 \ldots \ldots \ldots$ & 2,9 & 3,4 & & & \\
\hline $1870-1929 \ldots \ldots \ldots$ & 3,8 & 6,2 & & & \\
\hline
\end{tabular}

* Dato de población correspondiente a 1930.

Fuente: Para los valores anuales del comercio cfr. cuadro 2, columnas (a) y (b). Datos de población tomados de Estadísticas Históricas (1985), vol. I, p. 9.

podrían contribuir a una revaloración del papel del sector externo en el crecimiento económico de México durante el período ${ }^{79}$.

El gráfico 6 contiene también una serie de los valores anuales de las exportaciones netas de metálico, mientras que el cuadro 2 ofrece datos anuales tanto de las exportaciones netas como de las totales [columnas $(\mathrm{g})$ y $(f)$, respectivamente]. El énfasis en las transferencias netas busca llamar la atención sobre un hecho poco reconocido en la literatura: pese al papel de México como exportador de metales preciosos, en algunos momentos el país requirió importar sumas cuantiosas de dinero, lo cual disminuyó el monto de los flujos netos al exterior. Esto sucedió por primera vez alrededor de 1905, cuando el gobierno mexicano adquirió oro del mercado internacional para apoyar la reforma monetaria que lo sujetaría a ese patrón de cambio ${ }^{80}$. Entre 1916 y 1921 el país se vio por segunda ocasión en

79 Una versión modernizada de la visión convencional de que el sector exportador arrojó pocos beneficios al crecimiento económico del pals es Catao (1992). Una interpretación distinta, según la cual el impacto del sector exportador sobre el resto de la economía se vio limitado más por su modesto crecimiento de largo plazo que por sus características intrínsecas es sustentada en Bulmer-Thomas (1996), pp. 60-70 y nota 45.

${ }^{80}$ Entre 1905 y 1906 se importó oro por un monto total de 30 millones de dólares, la mayor parte através de Estados Unidos. US Department of Commerce, núm. 30, (1907), p. 268. 
la necesidad de importar gruesas cantidades de oro (y en mucha menor medida de plata), primero para estabilizar la moneda y regresar al patrón oro tras la crisis del sistema monetario provocada por la revolución, y luego para aliviar la severa escasez de medios de pago que, a juzgar por el monto de las importaciones de metálico, se prolongó por varios años ${ }^{81}$. De hecho, a partir de 1916 y hasta el final del período, México se convirtió en un importador neto de metálico, como se observa en la gráfica y de forma más precisa en el cuadro 2 [columna $(g)]^{82}$.

Como se ha dicho ya, una parte de las exportaciones netas de metálico se utilizó para el pago de importaciones. A ese mismo propósito contribuyeron los flujos de inversión extranjera, algunos de los cuales se adivinan en los picos que registró el déficit comercial [columna ( $e$ ) en el cuadro 2] en 1881 y en 1889 , esta última vez pese al aumento considerable que habían experimentado las exportaciones de mercancías [columna (b)]. Una vez que las exportaciones crecieron lo suficiente para soportar el peso de las importaciones, las transferencias de metálico se destinaron en mayor medida al pago de deudas, intereses y dividendos, y otras remisiones de particulares al extranjero. Desafortunadamente, con los datos de que se dispone hasta el momento no es posible contabilizar el monto anual de los recursos públicos y privados comprometidos en pagos al exterior. Como tampoco conocemos qué parte de estos pagos pudo cubrirse con inversiones extranjeras, es claro que las exportaciones netas de metálico no agotan esas transacciones ni ofrecen una medida exacta del déficit por cuenta corriente. Ofrecen, sin embargo, una primera aproximación a las transferencias anuales de recursos que desde México se hicieron con el propósito de saldar ese déficit, lo que nos coloca en una mejor perspectiva para analizar la posición internacional del país e intentar un primer acercamiento al estudio de la balanza de pagos ${ }^{83}$.

Finalmente, las nuevas series del comercio exterior mexicano se reproducen en el cuadro 2.

${ }^{81}$ El mejor estudio sobre el tema publicado hasta hoy es el de Cárdenas y Manns (1992), pp. 447-470. Sobre los problemas monetarios durante la revolución véase también Torres Gaytán (1990), capítulo IX.

${ }^{82}$ Entre 1916 y 1921 se importaron 104 millones de dólares en monedas de oro y (en una proporción mucho menor) plata, sobre todo de Estados Unidos. United States Treasury Department (1893-1930), passim.

${ }^{83}$ Luis Cerdá excluye correctamente las remisiones de metálico de la balanza de comercio, pero se equivoca al considerarlas en su totalidad como pertenecientes a la cuenta de capital, lo que lo lleva a pensar que la suma de estas remisiones y el saldo comercial representa el saldo de la balanza de pagos. Cerdá (1992), pp. 16-17, cuadro 1 y gráfica 14. 


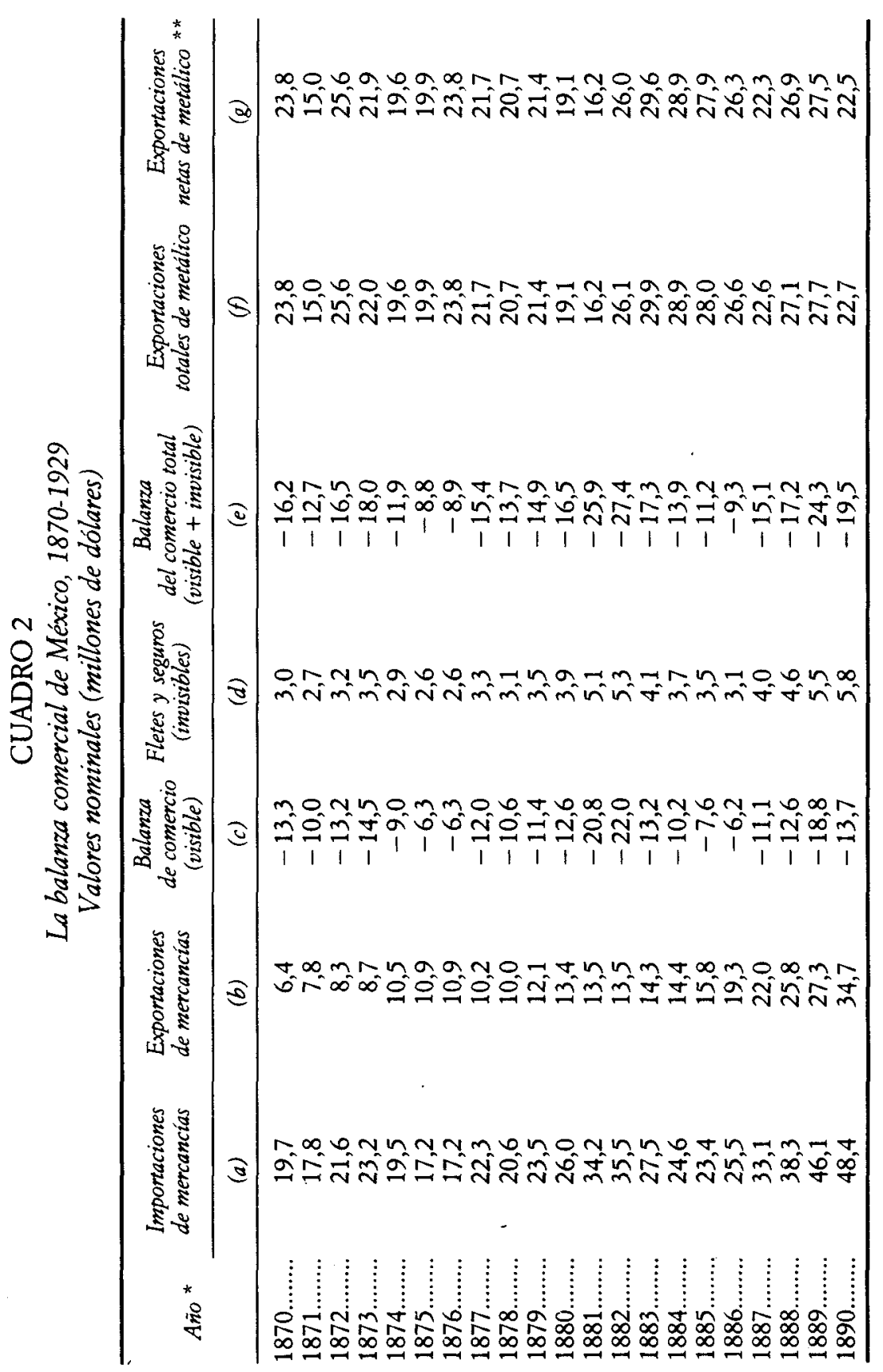




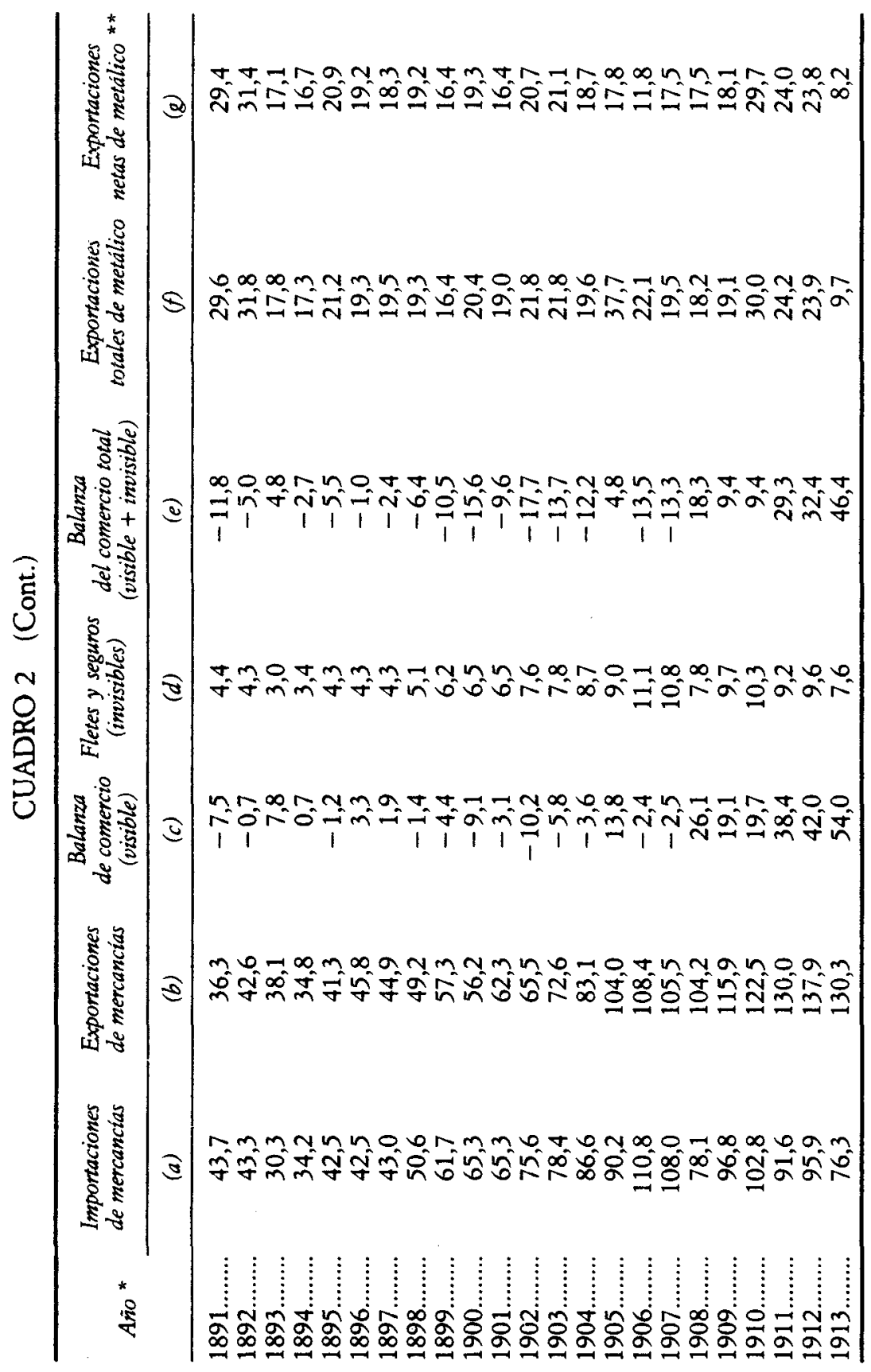




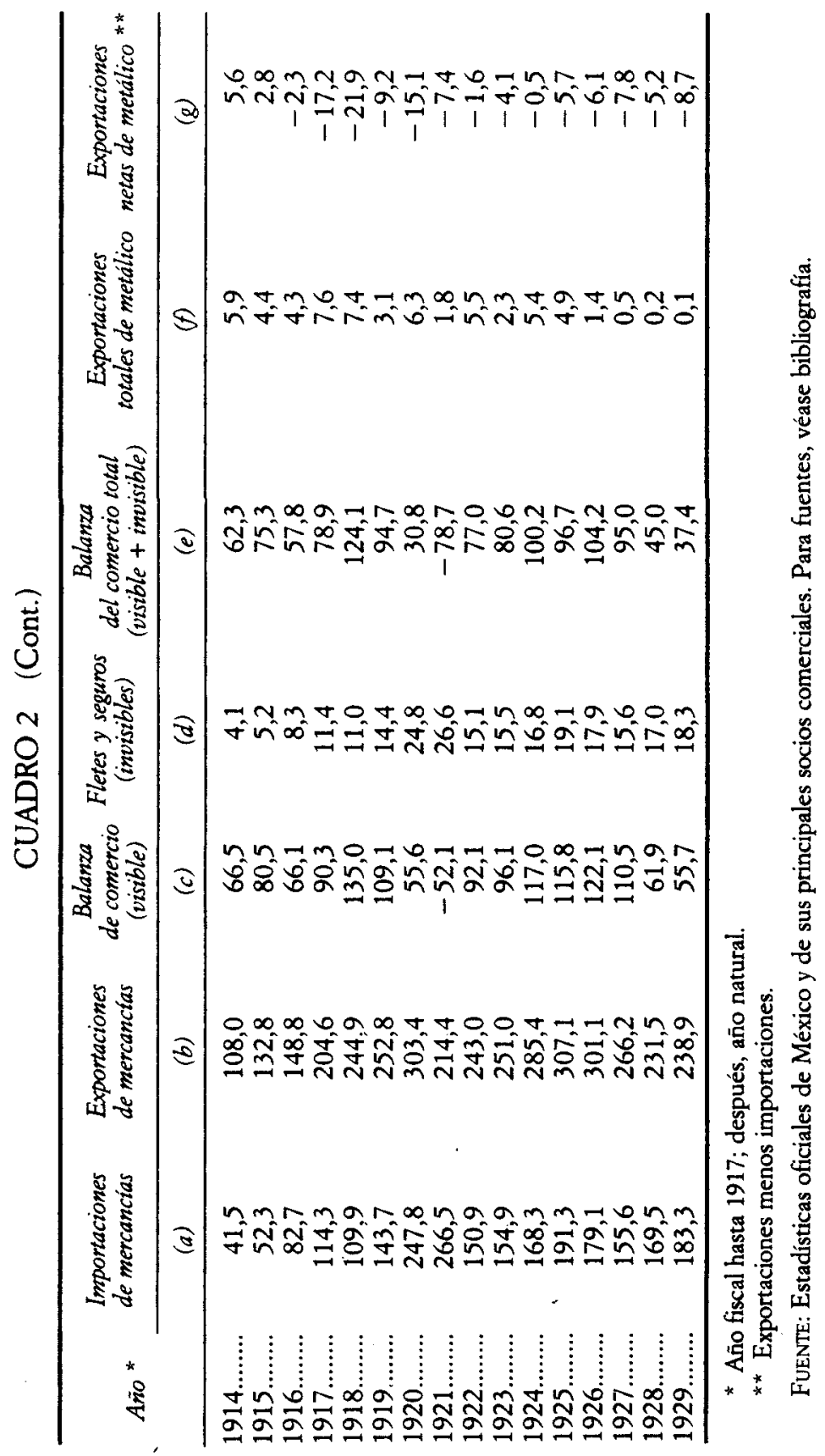




\section{CONCLUSIONES}

La reconstrucción de las series oficiales del comercio exterior de México a partir de las cifras que ofrecen sus principales socios comerciales ha permitido, en primer lugar, una evaluación de la consistencia, confiabilidad y comparabilidad de las estadísticas mexicanas disponibles. En términos generales, se pueden distinguir tres etapas en el registro oficial del comercio exterior mexicano. La primera, perteneciente a la era preestadística, se caracteriza por una compilación irregular de los flujos comerciales, por la ausencia de criterios definidos y consistentemente aplicados en la valoración del comercio y por un grado importante de subestimación de los valores totales, debido fundamentalmente al contrabando. La consolidación del régimen porfirista hizo posible un mayor control sobre el territorio, mejoró la capacidad administrativa del Estado y permitió establecer criterios uniformes para el registro de los flujos comerciales. Estos factores, aunados a una progresiva liberalización de las barreras impuestas al comercio exterior y a una mejora sustancial en la infraestructura del transporte terrestre, contribuyeron a disminuir el contrabando hasta hacerlo insignificante. Entre 1892 y 1912 las estadísticas mexicanas poseen un alto grado de consistencia y confiabilidad, que, particularmente en el caso de las importaciones, las hace susceptibles de utilización para el análisis histórico. Aunque las estadísticas de exportación se ven favorecidas también por los factores mencionados, los criterios de agrupación y deficiencias en las valoraciones afectan negativamente la comparabilidad y utilidad analítica de estas series tal y como se presentan en las fuentes oficiales. Por otra parte, la ruptura del orden político y la reaparición del contrabando incidieron negativamente sobre el registro de los flujos comerciales durante el decenio de 1910. Las deficiencias en las fuentes oficiales se extienden hasta los primeros años de 1920, pues aunque la publicación de las cuentas comerciales se regularizó rápidamente, los criterios y valoraciones adoptados entonces son dudosos y poco consistentes. En el último lustro del período las cifras oficiales mexicanas recobran cierta consistencia, aunque su comparabilidad es afectada por la adopción de un nuevo sistema de clasificación del comercio a nivel internacional (la clasificación de Bruselas), al cual México se adhirió con cierto retraso.

En segundo lugar, el ejercicio de reconstrucción que aquí se presenta ha permitido llenar las brechas de información existentes en las fuentes oficiales y rectificar los valores totales que emergen de éstas. Por primera vez se dispone de valores anuales del comercio para el período 1870-1892 
y para la década de 1910, y por primera vez es posible distinguir entre el intercambio de mercancías y las transferencias de metálico. Y, lo que es quizá más importante, las series propuestas han sido elaboradas a partir de criterios explícitos, que son susceptibles de verificación. Es posible, entonces, que sean rectificadas a medida que mejore nuestro conocimiento de los patrones del comercio internacional de México, que se afinen los criterios de agrupación, o que se disponga de fuentes más completas y precisas sobre el intercambio bilateral con los socios principales.

Las series así reconstruidas han permitido una primera aproximación a la evolución del comercio exterior y de la balanza comercial de México en el largo plazo. De ella emerge una idea más precisa del ritmo, los ciclos y las dimensiones de la apertura más significativa del país al comercio internacional hasta épocas recientes, a partir de la cual será posible revaluar el papel del sector externo en el desarrollo económico de México en la etapa del capitalismo liberal. Un análisis somero de esta evolución ha permitido sugerir que, partiendo de niveles extremadamente modestos en los años setenta, el despegue del sector exportador característico de esta etapa tuvo lugar en la década de 1880, auspiciado por una importante inyección de recursos en la construcción de infraestructura y en el desarrollo de las actividades mineras. Las crisis internacionales de 1893 y 1907 (que coincidieron con crisis económicas internas de diversa magnitud) impusieron un freno o retroceso transitorio a la tendencia ascendente, pero fuera de estos altibajos el crecimiento exportador prosiguió con pocos sobresaltos durante prácticamente toda la década de 1910. A lo largo de este proceso, las importaciones crecieron también de manera consistente, aunque a un ritmo mucho menor. En consecuencia, México disfrutó de una balanza comercial favorable desde fines del decenio de 1900 hasta la crisis de 1929. Las exportaciones de metálico, que en las primeras décadas contribuyeron a saldar el déficit comercial, se destinaron en medida creciente al pago de invisibles de la cuenta corriente, aunque en épocas de inestabilidad representaron también fugas de capital. Las condiciones creadas por la revolución, como la suspensión de pagos al exterior y la escasez de metálico para la circulación interna, redujeron drásticamente esas transferencias y, entre 1916 y 1929, convirtieron a México en un importador neto de metálico.

La guerra civil que tuvo lugar entre 1910 y 1917 afectó de manera desigual a las dos dimensiones del comercio. Danó en mucha mayor medida a las importaciones, debido a la fractura del mercado interno, a la interrupción transitoria de muchas actividades productivas y al desvío de los recursos derivados del comercio a las necesidades de la lucha armada. Las cifras 
extraordinarias que alcanzaron las importaciones en 1920 y 1921 indican en parte las dimensiones que alcanzaron las pérdidas en el stock de capital fijo durante los años de guerra. En cambio, las exportaciones vivieron un auge durante la década de 1910, al que contribuyeron tanto la localización de las actividades exportadoras como los altos precios internacionales en la coyuntura de la guerra mundial. En 1921 la balanza comercial de México se vio nuevamente afectada por la confluencia de una crisis internacional con una crisis interna, aunque la restricción de las importaciones permitió recuperar rápidamente el saldo favorable en los siguientes años. Finalmente, las nuevas series sugieren un desempeño desigual del sector exportador en los años veinte, como consecuencia de los factores políticos e institucionales que afectaron la relación con los grupos exportadores (latifundistas, inversionistas extranjeros), del agotamiento del primer boom petrolero y de los cambios en la demanda internacional. En el balance, la ruptura revolucionaria que marcaría la originalidad de la experiencia mexicana en el contexto latinoamericano aparece matizada por ciertas líneas de continuidad: a la postre, fue el colapso del comercio internacional en 1929 y no la revolución lo que puso fin a la primera era del capitalismo liberal en México ${ }^{84}$.

\section{BIBLIOGRAFÍA}

\section{Fuentes primarias}

1. México

Publicadas por la Secretaria de Hacienda y Crédito Público:

- (1913, 1914, 1921, 1922): Anuario de estadística fiscal 1911-1912, 1912-1913, 1918, 1919, México.

- (1920-1928): Anuario del comercio exterior y navegación, México.

- (1891), Boletín Comercial de la Secretaría de Hacienda... de los Estados Unidos Mexicanos, México.

- (1895-1911): Boletín de estadística fiscal, números correspondientes a los años fiscales 1893-1894 a 1910-1911, México.

- (1917-1918): Boletín de estadística fiscal, tt. I-IV, México.

- (1901): Comercio exterior y navegación. Año fiscal de 1898-1899, núm. 215, México.

- (1902): Comercio exterior y navegación. Año fiscal de 1899-1900, núm. 225a, México.

${ }^{84}$ Como bien dice Alan Knight: «Puede argumentarse que en México -como en otras economías "periféricas"- los síntomas de la depresión precedieron en hasta tres años a 1929; pero el fracaso del desarrollo bacia fuera no puede llevarse tan lejos como la Revolución». Knight (1990), p. 648, nota 1366. 
- (1892): Importaciones 1889 a 1890. Primer semestre-segundo semestre-año fiscal. Noticias formadas bajo la dirección de Javier Stávoli, México.

- (1879 y 1880): Memoria de Hacienda y Crédito Público, 1877-1878 y 1878-1879, México.

- (1880): Noticia de la importación y exportación de mercancías en los años fiscales de 1872 a 1873, 1873 a 1874 y 1874 a 1875, formada bajo la dirección de José M. ${ }^{a}$ Garmendia, México.

- (1878-1893): Noticia de la exportación de mercancías de la República Mexicana, México.

- (1879): Noticia pormenorizada del costo que tienen las mercancias extranjeras que se importan por el puerto de Veracruz, México.

- (1888): Noticias de las mercancías importadas en los dos primeros semestres de los años fiscales de 1884 a 1885 y 1885 a 1886. Formadas bajo la dirección de J. Stávoli, México.

Publicadas por otras agencias del gobierno:

Banco Nacional de Comercio Exterior (1937): México exportador, México.

COMisión MONETARIA (1904), Actas de las juntas generales y documentos a ellas anexos, México.

Departamento de la Estadística Nacional (1923): Anuario estadístico. Comercio exterior y navegación. Años 1920, 1921 y 1922, México.

- (1926-1930): Anuario estadístico. Comercio exterior y navegación. Años de 1925 a 1928, México.

- (1932): Anuario de 1930, México.

- (1924): Boletín del Departamento de La Estadística Nacional, núms. 9-11, México.

Dirección General de Estadística (1939): Anuario estadístico de los Estados Unidos Mexicanos, México.

Ferrocarriles Nacionales de México (1932): México Económico, 1928-1930, México.

Ministerio de Fomento (1893-1897): Anuario estadístico de la República Mexicana, México.

- (1889): Boletín semestral de la estadística de la República Mexicana, a cargo del Dr. Antonio Peñafiel, núm. 4, México.

- (1889-1892): Boletin Semestral de la Dirección General de Estadística, México.

2. Los socios comerciales

\section{Alemania}

Monatliche Nachweise über den auswärtigen Handel Deutschlands, berausgegeben vom Statistischen Reichsamt (1925-1930), Berlin, Reimar Hobbing.

Statistik des Deutschen Reichs. Auswärtiger Handel deutschen Zollgebiets im Jabre..., berausgegeben vom Kaiserlichen Statistischen Amt (1891-1912), Berlin, Buttkammer und Mühlbrecht.

Estados Unidos

Historical Statistics of the United States. Colonial Times to 1970 (1989), part 2, Nueva York, Kraus International Publications. 
Statistical Abstract of the United States (1888-1943), Washington, Government Printing Office.

United States Department of Commerce and Labor, Bureau of Manufactures (1904, 1905, 1906): Commercial Relations of the United States with Foreign Countries during the Year 1903, 1904, 1905, Washington, Government Printing Office.

United STATEs DePartment of State (1890): Reports from the Consuls of the United States on the Commerce, Manufactures, etc., of their Consular Districts, núm. 122, Washington, Government Printing Office.

United States House of Representatives (1872-1892): Annual Report of the Chief of the Bureau of Statistics on the Commerce and Navigation of the United States for the Fiscal Year ended June, 30 (1871 a 1892), Washington, Government Printing Office.

United States Treasury Department (1889): Commerce of the United States and Other Foreign Countries with Mexico, Central America, the West Indies, and South America, Washington, Government Printing Office.

- (1893-1930): The Foreign Commerce and Navigation of the United States for the Year Ending..., Washington, Government Printing Office (el autor y el

- título varían).

Francia

Direction Générale Des Douanes (1872-1931): Tableau Général du Commerce de la France avec ses Colonies et les Pussances Étrangeres Pendant l'Année..., Paris, Imprimerie Nationale (el título puede variar).

Gran Bretaña

Great Brtain Customs Establishment. Statistical Office (1870-1930): Annual Statement of the Trade and Navigation of the United Kingdom with Foreign Countries and British Possessions in the Year..., London (el título y el editor varian).

Otras fuentes primarias

Arnauné, August (1911): Le Commerce Extérieur et les Tarifs de Douane, Paris, Librairie Félix Alcan.

DUBLÁ, Manuel, y LozANo, José María (1877-1910): Legislación mexicana o colección completa de las disposiciones legislativas expedidas desde la independencia de la República, vols. 8-42, México.

Henius, Frank (1946): Dictionary of Foreign Trade, New York, Prentice Hall.

InstTTut International D'AGriculture (1914): Notes sur les Statistiques du Commerce Exterieur dans les Différents Pays, Rome, Imprimerie de la Chambre des Députés.

LEAGUE OF NATIONS (1927-1928): Memorandum on International Trade and Balances of Payments. 1912-1926, 2 vols., Gèneve, Publications of the League of Nations.

- (1928): Memorandum... 1913-1927, vol. I, Gèneve, Publications of the League of Nations.

- (1930-1931): Memorandum.. 1927-1929, 3 vols., Gèneve, Series of League of Nations Publications. 
ROMERo, Matías (1898): Geographical and Statistical Notes on Mexico, New York and London, G. P. Putnam's Sons.

Sherwell, G. Butler (1929): Mexico's Capacity to Pay. A General Analysis of the Present International Economic Position of Mexico, Washington.

MooD, James (1930): Handbook of Foreign Currency and Exchange, Washington, Government Printing Office.

ZuCKermann, S. (1921): Statistischer Atlas zum Welthandel, Berlin, Otto Elsner.

\section{Fuentes secundarias}

Allen, R. G. D., y Ely, J. E. (eds.) (1953): International Trade Statistics, New York, Wiley.

BEATT, Edward (2000): «The impact of Foreign Trade on the Mexican Economy: Terms of Trade and the Rise of Industy 1880-1923», Joumal of Latin American Studies, núm. 32, pp. 399-433.

Bulmer-Thomas, Victor (1996): The Economic History of Latin America Since Independence, Cambridge, Cambridge University Press.

CÁRDENAS, Enrique (1987): La industrialización mexicana durante la Gran Depresión, México, El Colegio de México.

CáRDENAS, Enrique, y MANNS, Carlos (1992): «Inflación y estabilización monetaria en México durante la revolución», en CÁrdenAs, Enrique (comp.): Historia Económica de México. Lecturas, vol. 3, México, FCE.

Carmagnani, Marcello (1994): Estado y mercado. La economía pública del liberalismo mexicano, 1850-1911, México, FCE-El Colegio de México-Fideicomiso Historia de las Américas.

CataO, Luis A. V. (1991): «The Transmission of Long Cycles Between "Core" and "Periphery" Economies: A Case Study of Brazil and Mexico, c. 18701940», $\mathrm{PhD}$ dissertation, University of Cambridge.

- (1992): The Failure of Export-Led Growth in Brazil and Mexico c. 1870-1930, London, Institute of Latin American Studies.

CERDÁ, Luis (1991): «¿Causas económicas de la Revolución Mexicana?», Revista Mexicana de Sociologia, LIII:1.

- (1992): Exchange-Rate and Monetary Policies in Mexico from Bimetallism to the Gold Standard: 1890-1910, México, ITAM, Documentos de Trabajo.

COATSWORTH, John H. (1990): Los origenes del atraso. Nueve ensayos de bistoria económica de México en los siglos XVIII y XIX, México, Alianza Editorial Mexicana.

Conen, B. J. (1969): Política de balanza de pagos, Madrid, Alianza Universidad.

Cosío VIllegas, Daniel (coord.) (1955-1972): Historia moderna de México, 10 tomos, México, Hermes.

- (1985): Estadísticas bistóricas de México, 2 vols., México, INEGI-INAH.

El Colfgio de México (1960): Estadísticas económicas del porfiriato. 1. Comercio exterior de México; 1877-1911, México, El Colegio de México.

Federico, Giovanni, y Tena, Antonio (1991): «On the Accuracy of Foreign Trade Statistics (1909-1935): Morgenstern Revisited», Explorations in Economic History, núm. 28, pp. 259-273.

FOREMAN-PECK, James (1995): Historia económica mundial. Relaciones económicas internacionales desde 1850, 2.a ed., Madrid, Prentice Hall. 
HaBer, Stephen (ed.) (1995): How Latin America Fell Behind. Essays on the Economic Histories of Brazil and Mexico, 1800-1914, Stanford, Stanford University Press.

- (comp.) (1997): Cómo se rezagó la América Latina. Ensayos sobre las bistorias económicas de Brasil y México, 1800-1914, México, FCE, Lecturas de El Trimestre Económico.

Helleiner, G. K. (1972): Comercio intemacional y desarnollo económico, Madrid, Alianza Universidad.

Herrera Canales, Inés (1977): El comercio exterior de México, 1821-1875, México, El Colegio de México.

IbarRa Bellón, Araceli (1998): El comercio y el poder en México, 1821-1864. La lucha por las fuentes financieras entre el Estado central y las regiones, México, FCE.

KAPP, Bernard (1974): «Les relations économiques extérieures du Mexique (1821-1911) d'après les sources françaises», Ville et commerce (deux essais d'bistoire hispanoamericaine), Paris, Editions Klincksieck.

KaTZ, Friedrich (1986): «Mexico: Restored Republic and Porfiriato, 1867-1910», en Leslie Bethell (ed.): The Cambridge History of Latin America, vol. V, C. 1870-1930, Cambridge, Cambridge University Press, pp. 3-78.

KNIGHT, Allan (1990): The Mexican Revolution, vol. 2, Counter-Revolution and Reconstruction, Lincoln, University of Nebraska Press.

KunTz FICKER, Sandra (2001): «El comercio México-Estados Unidos, 1870-1929: reconstrucción estadística y tendencias generales», Mexican Studies/Estudios Mexicanos, 17:1 (Winter), pp. 71-107.

- (2002): «Institutional Change and Foreign Trade in Mexico, 1870-1910», en BorTz, Jeffrey, y HABER, Stephen (eds.): The Mexican Economy, 1870-1930. Essays on the Economic History of Institutions, Revolution and Growth, Stanford, Stanford University Press.

- (manuscrito inédito), «The Mexican Revolution Export Boom. Characteristics and Contributing Factors».

LANCASTER, Kelvin (1977): Economia moderna 2, Madrid, Alianza Universidad.

LeRman Alperstein, Aída (1989): Comercio exterior e industria de transformación en México, 1910-1920, México, UAM-Xochimilco-Plaza y Valdés Editores.

- (1990): «Comercio exterior en México: 1920-1935», Investigación Económica, núm. 192, pp. 141-154.

Lorey, David E. (ed.) (1990): United States-Mexico Border Statistics since 1900, Los Angeles, UCLA Latin American Center Publicacions.

Maizels, Alfred (1952): «Oversea Trade», en Kendall, Maurice G., y HrLl, A. Bradford (eds.): The Sources and Nature of the Statistics of the United Kingdom, vol. I, London, The Royal Statistical Society-Oliver and Boyd.

MEYER, Jean (1986): «Mexico: Revolution and Reconstruction in the 1920s», en Bethell, Leslie (ed.): The Cambridge History of Latin America, vol. V, C. 1870-1930, Cambridge, Cambridge University Press, pp. 155-196.

MrTCHELL, B. R. (1983): Intemational Historical Statistics. The Americas and Australasia, Detroit, Gale Research Co.

- (1992): International Historical Statistics. Europe, 1750-1988, New York, Stockton Press. 
Morgenstern, Oskar (1963): On the Accuracy of Economic Observations (1950), 2. ${ }^{a}$ ed., Princeton, Princeton University Press.

OCAMPO, José Antonio (1980): «Las importaciones colombianas en el siglo XIX», en UrRutia, Miguel (ed.): Ensayos sobre bistoria económica colombiana, Bogotá, Presencia.

PaLYI, Melchior (1972): The Twilight of Gold, Chicago, Henry Regnery Company.

PlatT, D. C. M. (1971): «Problems in the Interpretation of Foreign Trade Statistics before 1914», Joumal of Latin American Studies, 3:2, pp. 119-130.

Prados de la Escosura, Leandro (1986): «Una serie anual del comercio exterior español (1821-1913)», Revista de Historia Económica, IV:1, pp. 103-150.

- (1985): Los Presidentes de México ante la Nación, México, Cámara de Diputados.

Riguzzi, Paolo (1992): «México, Estados Unidos y Gran Bretaña, 1867-1910: una difícil relación triangular», Historia Mexicana, XII:3, pp. 365-436.

- (2000): «Constitución, libertad económica y libre cambio en la experiencia mexicana, 1850-1896», en CARMAGnaNI, Marcelo (coord.): Constitucionalismo y orden liberal en América Latina, 1850-1920, Torino, Otto.

- (de próxima publicación), Las relaciones económicas internacionales de México, 1867-1914, México.

Rodríguez R., Jorge, y MCGReEvey, William P. (1970): «Colombia: comercio exterior 1835-1962», en URrutTA, Miguel, y Arrubla, Mario (eds.): Compendio de estadisticas históricas de Colombia, Bogotá, Universidad Nacional de Colombia.

RoSENZWEIG, Fernando (1985): «El comercio exterior», en Cosío VILlEGAS, Daniel (coord.): Historia moderna de México. El porfiriato. La vida económica, vol. II (3. a ed.), México, Hermes.

- (1989): El desarrollo económico de México, 1800-1910, México, El Colegio Mexiquense-ITAM.

SALvuCCI, Richard J. (1991): «The Origins and Progress of U.S.-Mexican Trade, 1825-1884: "Hoc opus, hic labor est"», Hispanic American Historical Review, $71: 4$, pp. 697-735.

SChell, William, Jr. (1996): «Money as Commodity: Mexico's Conversion to the Gold Standard, 1905», Mexican Studies/Estudios Mexicanos, 12:1.

Sierra, Carlos J., y MarTínez VERA, Rogelio (1973): Historia y legislación aduanera de México, México, Secretaría de Hacienda y Crédito Público.

SIMON, Matthew (1960): «The United States Balance of Payments, 1861-1900», en Trends in the American Economy in the Nineteenth Century. Studies in Income and Wealth, 24, Princeton, Princeton University Press, pp. 629-659.

Tena Junguito, Antonio (1985), «Una reconstrucción del comercio exterior español, 1914-1935: la rectificación de las estadísticas oficiales», Revista de Historia Económica, III:1, pp. 77-119.

- (1992): Las estadísticas bistóricas del comercio internacional: fiabilidad y comparabilidad, Madrid, Banco de España.

TORREs Gaytán, Ricardo (1990): Un siglo de devaluaciones del peso mexicano, 6. ed., México, Siglo XXI. 


\section{APÉNDICE}

Tipo de cambio de las distintas monedas con respecto al dólar, 1870-1929 (promedio anual)

\begin{tabular}{|c|c|c|c|c|c|}
\hline & $\begin{array}{c}M X: \\
\text { importaciones } \\
\text { (dólares } \\
\text { por peso) }\end{array}$ & $\begin{array}{c}\text { MX: } \\
\text { exportaciones } \\
\text { (dólares } \\
\text { por peso) }\end{array}$ & $\begin{array}{c}G B \\
\text { (dólares por } \\
\text { libra esterlina) }\end{array}$ & $\begin{array}{c}F R \\
\text { (dólares } \\
\text { por franco) }\end{array}$ & $\begin{array}{c}D T \\
\text { (dólares } \\
\text { por marco) }\end{array}$ \\
\hline $1870 \ldots$. & 1 & 1,04 & 4,8665 & 0,2 & 0,25 \\
\hline $1871 \ldots .$. & & 1,04 & $\begin{array}{c}\text { La misma } \\
\text { hasta } 1913\end{array}$ & $\begin{array}{l}\text { La misma } \\
\text { hasta } 1913\end{array}$ & $\begin{array}{l}\text { La misma } \\
\text { hasta } 1913\end{array}$ \\
\hline $1872 \ldots .$. & 1 & 1,038 & & & \\
\hline $1873 \ldots \ldots$ & 1 & 1,033 & & & \\
\hline $1874 \ldots \ldots$ & 1 & 1,018 & & & \\
\hline $1875 \ldots$. & & 0,989 & & & \\
\hline $1876 \ldots .$. & & 0,927 & & & \\
\hline $1877 \ldots .$. & 1 & 0,910 & & & \\
\hline $1878 \ldots .$. & & 0,910 & & & \\
\hline $1879 \ldots$. & & 0,900 & & & \\
\hline $1880 \ldots$. & & 0,890 & & & \\
\hline $1881 \ldots .$. & & 0,894 & & & \\
\hline $1882 \ldots$. & & 0,882 & & & \\
\hline $1883 \ldots \ldots$ & & 0,875 & & & \\
\hline $1884 \ldots$. & 1 & 0,864 & & & \\
\hline $1885 \ldots .$. & 1 & 0,816 & & & \\
\hline $1886 \ldots .$. & & 0,790 & & & \\
\hline $1887 \ldots \ldots$ & 0,759 & 0,759 & & & \\
\hline $1888 \ldots$. & 0,739 & 0,739 & & & \\
\hline $1889 \ldots$. & 0,758 & 0,758 & & & \\
\hline $1890 \ldots$. & & 0,837 & & & \\
\hline $1891 \ldots .$. & & 0,837 & & & \\
\hline $1892 \ldots$. & 1 & 0,657 & & & \\
\hline $1893 \ldots$. & 1 & 0,539 & & & \\
\hline $1894 \ldots$. & 1 & 0,514 & & & \\
\hline $1895 \ldots$. & 1 & 0,536 & & & \\
\hline $1896 \ldots .$. & 1 & 0,502 & & & \\
\hline $1897 \ldots$. & 1 & 0,448 & & & \\
\hline $1898 \ldots$. & 1 & 0,472 & & & \\
\hline $1899 \ldots$. & 1 & 0,476 & & & \\
\hline $1900 \ldots$. & 1 & 0,489 & & & \\
\hline $1901 \ldots .$. & 1 & 0,441 & & & \\
\hline $1902 \ldots .$. & 1 & 0,398 & & & \\
\hline $1903 \ldots .$. & 1 & 0,441 & & & \\
\hline $1904 \ldots .$. & 0,483 & 0,483 & & & \\
\hline
\end{tabular}




\begin{tabular}{|c|c|c|c|c|c|}
\hline & $\begin{array}{c}M X \\
\text { importaciones } \\
\text { (dólares } \\
\text { por peso) }\end{array}$ & $\begin{array}{c}M X: \\
\text { exportaciones } \\
(\text { dólares } \\
\text { por peso })\end{array}$ & $\begin{array}{c}G B \\
\text { (dólares por } \\
\text { libra esterlina) }\end{array}$ & $\begin{array}{c}F R \\
\text { (dólares } \\
\text { por franco) }\end{array}$ & $\begin{array}{c}D T \\
\text { (dólares } \\
\text { por marco) }\end{array}$ \\
\hline $1905 \ldots$. & 0,4984 & 0,500 & & & \\
\hline $1906 \ldots .$. & 0,4984 & 0,500 & & & \\
\hline $1907 \ldots .$. & 0,4984 & 0,497 & & & \\
\hline $1908 \ldots .$. & 0,4984 & 0,497 & & & \\
\hline $1909 \ldots$. & 0,4984 & 0,498 & & & \\
\hline $1910 \ldots$. & 0,4984 & 0,498 & & & \\
\hline $1911 \ldots$. & 0,4984 & 0,497 & & & \\
\hline $1912 \ldots .$. & 0,4984 & 0,497 & & & $\nabla$ \\
\hline $1913 \ldots \ldots$ & & 0,481 & 4,8665 & 0,2 & 0,25 \\
\hline $1914 \ldots .$. & 0,4984 & 0,303 & 5,0925 & 0,2031 & 0,2511 \\
\hline $1915 \ldots$. & & 0,090 & 4,8850 & 0,1848 & 0,2181 \\
\hline $1916 \ldots .$. & & 0,042 & 4,8900 & 0,1762 & 0,1924 \\
\hline $1917 \ldots$. & & 0,525 & 4,8850 & 0,1797 & 0,1644 \\
\hline $1918 \ldots$. & 0,4984 & 0,553 & 4,8850 & 0,1851 & 0,1876 \\
\hline $1919 \ldots .$. & 0,4984 & 0,504 & 4,6425 & 0,1593 & 0,0855 \\
\hline $1920 \ldots \ldots$ & 0,4984 & 0,498 & 3,5975 & 0,0737 & 0,0165 \\
\hline $1921 \ldots \ldots$ & 0,4984 & 0,489 & 3,8675 & 0,0774 & 0,0149 \\
\hline $1922 \ldots .$. & 0,4984 & 0,488 & 4,5325 & 0,0864 & 0,0030 \\
\hline $1923 \ldots$. & 0,4984 & 0,487 & 4,7525 & 0,0612 & 0,000019 \\
\hline $1924 \ldots .$. & 0,4984 & 0,484 & 4,5225 & 0,0512 & 0,2393 \\
\hline $1925 \ldots$. & 0,4984 & 0,494 & 4,9475 & 0,0516 & 0,2498 \\
\hline $1926 \ldots .$. & 0,483 & 0,483 & 4,8582 & 0,0324 & 0,2380 \\
\hline $1927 \ldots .$. & 0,473 & 0,473 & 4,8610 & 0,0392 & 0,2376 \\
\hline $1928 \ldots$. & 0,481 & 0,481 & 4,8662 & 0,0392 & 0,2386 \\
\hline $1929 \ldots$. & 0,482 & 0,482 & 4,8569 & 0,0392 & 0,2386 \\
\hline $1930 \ldots$. & 0,471 & 0,471 & 4,8621 & 0,0393 & 0,2385 \\
\hline
\end{tabular}

NOTAS Y FUENTES:

El cuadro presenta el tipo de cambio utilizado en la conversión del valor del comercio a dólares. En el caso de las importaciones $\mathrm{MX}$ se incluye el dato sólo cuando se dispone de las cifras correspondientes del comercio.

$M X$ (importaciones): Las fuentes oficiales utilizan una tasa de cambio legal a la par con el dólar durante la mayor parte del período. Sin embargo, existen dudas sobre la tasa aplicada en dos subperíodos: los años fiscales 1887 a 1889 y 1926 a 1930 . En el primer caso, El Colegio... (1960), p. 518, presupone que las cifras están en «pesos fuertes» (o dólares) y las «convierte» a pesos. Fuentes de la época consideran, en cambio, que se trata de cifras en pesos, y ése es el supuesto que se asume aquí. Cfr. Boletín Comercial (1891), p. 5; Treasury Department (1889), pp. LXXIII-LXXV; Romero (1898), p. 157. En el segundo caso (1926 a 1930), la comparabilidad de las cifras MX empeora considerablemente si se considera el tipo legal, por lo que se decidió utilizar la tasa de cambio de mercado.

MX (exportaciones): Valores oficiales publicados originalmente en pesos. Para 1877-1910 
el tipo de cambio utilizado aquí se tomó de El Colegio... (1960), pp. 152-53, salvo los años 1881-1901, en los cuales se empleó la tasa de cambio implícita en las cifras de Comisión Monetaria (1904), que proporciona datos en pesos y en dólares. Para 1870-1876 y 1911-1929 se utilizó Estadísticas históricas (1985), vol. II, pp. 810-811. Para 1921 (año faltante en la última fuente) se recurrió a Mood (1930), p. 114.

Conforme a las fuentes utilizadas, los años 1870-1876 y 1911-1929 representan años naturales; el resto, años fiscales.

$G B, F R, D T$ : De 1914 a 1925 la tasa de cambio de cada moneda en dólares se calculó a partir de los porcentajes de depreciación propuestos en Palyi (1972), pp. 38-39. Para los demás años se utilizó Mood (1930); League of Nations (1930-1931), vol. I, pp. 110-115; Statistical Abstract (1931), p. 299.

Importaciones mexicanas procedentes de sus socios principales 1870-1913: años fiscales; 1914 en adelante: años naturales. Valor de factura f.o.b. en dólares

\begin{tabular}{|c|c|c|c|c|}
\hline & $M X-E U$ & $M X-G B$ & $M X-F R$ & $M X-D T$ \\
\hline \multicolumn{5}{|l|}{$1870 \ldots \ldots \ldots \ldots \ldots$} \\
\hline \multicolumn{5}{|l|}{$1871 \ldots \ldots \ldots \ldots \ldots . . . . . . . .}$. \\
\hline $1872 \ldots \ldots \ldots \ldots \ldots$ & -25 & -31 & 2 & \\
\hline $1873 \ldots \ldots \ldots \ldots \ldots$ & -32 & -35 & 0 & \\
\hline $1874 \ldots \ldots \ldots \ldots \ldots$ & -23 & -44 & 10 & \\
\hline \multicolumn{5}{|l|}{$1875 \ldots \ldots \ldots \ldots \ldots$} \\
\hline \multicolumn{5}{|l|}{$1876 \ldots \ldots \ldots \ldots \ldots \ldots$} \\
\hline \multicolumn{5}{|l|}{$1877 \ldots \ldots \ldots \ldots \ldots$} \\
\hline \multicolumn{5}{|l|}{$1878 \ldots \ldots \ldots \ldots \ldots$} \\
\hline \multicolumn{5}{|l|}{1879} \\
\hline \multicolumn{5}{|l|}{$1880 \ldots \ldots \ldots \ldots \ldots \ldots$} \\
\hline \multicolumn{5}{|l|}{$1881 \ldots \ldots \ldots \ldots \ldots \ldots$} \\
\hline \multicolumn{5}{|l|}{$1882 \ldots \ldots \ldots \ldots \ldots$} \\
\hline \multicolumn{5}{|l|}{$1883 \ldots \ldots \ldots \ldots \ldots$} \\
\hline $1884 \ldots \ldots \ldots \ldots \ldots$ & -27 & -36 & 34 & \\
\hline $1885 \ldots \ldots \ldots \ldots \ldots$ & -33 & 7 & 12 & \\
\hline \multicolumn{5}{|l|}{$1886 \ldots \ldots \ldots \ldots \ldots \ldots$} \\
\hline $1887 \ldots \ldots \ldots \ldots \ldots$ & -38 & & & \\
\hline $1888 \ldots \ldots \ldots \ldots \ldots$ & -36 & 42 & 51 & \\
\hline 1889 & -42 & 30 & 23 & \\
\hline \multicolumn{5}{|l|}{$1890 \ldots \ldots \ldots \ldots \ldots$} \\
\hline \multicolumn{5}{|l|}{$1891 \ldots \ldots \ldots \ldots \ldots . . . . . . .}$. \\
\hline $1892 \ldots \ldots \ldots \ldots \ldots$ & -28 & 5 & -11 & 4 \\
\hline $1893 \ldots \ldots \ldots \ldots \ldots$ & -13 & 0 & -10 & 6 \\
\hline $1894 \ldots \ldots \ldots \ldots \ldots$ & -4 & 0 & -22 & -9 \\
\hline
\end{tabular}




\begin{tabular}{|c|c|c|c|c|}
\hline & $M X-E U$ & $M X-G B$ & $M X-F R$ & $M X-D T$ \\
\hline $1895 \ldots \ldots \ldots \ldots \ldots$ & -7 & -6 & -24 & -8 \\
\hline $1896 \ldots \ldots \ldots \ldots \ldots$ & 1 & 10 & -15 & 0 \\
\hline $1897 \ldots \ldots \ldots \ldots \ldots$ & -5 & 1 & -21 & -5 \\
\hline $1898 \ldots \ldots \ldots \ldots \ldots$ & 0 & -1 & -15 & -8 \\
\hline $1899 \ldots \ldots \ldots \ldots \ldots$ & 9 & -7 & -19 & -11 \\
\hline $1900 \ldots \ldots \ldots \ldots \ldots$ & 2 & -13 & -27 & -3 \\
\hline $1901 \ldots \ldots \ldots \ldots \ldots . . . . . .$. & 0 & 9 & -26 & 9 \\
\hline $1902 \ldots \ldots \ldots \ldots \ldots$ & 1 & -6 & -23 & -9 \\
\hline $1903 \ldots \ldots \ldots \ldots \ldots$ & 5 & -10 & -16 & -1 \\
\hline $1904 \ldots \ldots \ldots \ldots \ldots . . . . . . .$. & -7 & -13 & -22 & 3 \\
\hline $1905 \ldots \ldots \ldots \ldots \ldots$ & -21 & 2 & -17 & 6 \\
\hline $1906 \ldots \ldots \ldots \ldots \ldots$ & -10 & 9 & -4 & \\
\hline $1907 \ldots \ldots \ldots \ldots \ldots$ & -7 & -24 & -19 & -6 \\
\hline $1908 \ldots \ldots \ldots \ldots \ldots$ & 9 & 7 & 12 & 9 \\
\hline $1909 \ldots \ldots \ldots \ldots \ldots$ & 2 & -1 & -10 & 0 \\
\hline $1910 \ldots \ldots \ldots \ldots \ldots$ & 7 & -4 & -16 & -9 \\
\hline $1911 \ldots \ldots \ldots \ldots \ldots . . . . . .$. & 6 & 9 & 7 & -5 \\
\hline $1912 \ldots \ldots \ldots \ldots \ldots$ & 9 & -11 & -2 & -9 \\
\hline \multicolumn{5}{|l|}{$1913 \ldots \ldots \ldots \ldots \ldots$} \\
\hline $1914 \ldots \ldots \ldots \ldots \ldots$ & & 41 & & \\
\hline $1915 \ldots \ldots \ldots \ldots \ldots$ & & -21 & & \\
\hline $1916 \ldots \ldots \ldots \ldots \ldots \ldots$ & 41 & & 6 & \\
\hline \multicolumn{5}{|l|}{$1917 \ldots \ldots \ldots \ldots \ldots \ldots$} \\
\hline $1918 \ldots \ldots \ldots \ldots \ldots \ldots$ & -23 & & -46 & \\
\hline $1919 \ldots \ldots \ldots \ldots \ldots$ & 28 & -1 & -40 & \\
\hline $1920 \ldots \ldots \ldots \ldots \ldots \ldots$ & 44 & -3 & -41 & \\
\hline $1921 \ldots \ldots \ldots \ldots \ldots$ & -3 & -18 & & \\
\hline $1922 \ldots \ldots \ldots \ldots \ldots$ & -3 & -15 & -48 & \\
\hline $1923 \ldots \ldots \ldots \ldots \ldots$ & -3 & 22 & -22 & \\
\hline $1924 \ldots \ldots \ldots \ldots \ldots \ldots$ & 13 & -2 & -24 & \\
\hline $1925 \ldots \ldots \ldots \ldots \ldots$ & 3 & 2 & -20 & -7 \\
\hline $1926 \ldots \ldots \ldots \ldots \ldots$ & 1 & -1 & -24 & -9 \\
\hline 1927 ................... & -4 & 0 & -35 & -11 \\
\hline $1928 \ldots \ldots \ldots \ldots \ldots$ & -3 & 8 & -32 & -5 \\
\hline $1929 \ldots \ldots \ldots \ldots \ldots$ & 2 & 0 & -32 & \\
\hline
\end{tabular}


Importaciones mexicanas: fuentes oficiales $M X$ y reconstrucción $S K$ (millones de dólares)

\begin{tabular}{|c|c|c|}
\hline & Totales MX & Mercancias SK \\
\hline 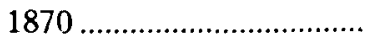 & 14,3 & 19,7 \\
\hline 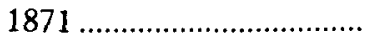 & & 17,8 \\
\hline 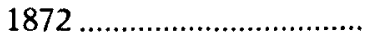 & 20,2 & 21,6 \\
\hline $1873 \ldots \ldots \ldots \ldots \ldots \ldots \ldots \ldots \ldots \ldots \ldots \ldots \ldots \ldots \ldots$ & 23,3 & 23,2 \\
\hline 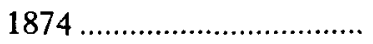 & 18,8 & 19,5 \\
\hline $1875 \ldots \ldots \ldots \ldots$ & & 17,2 \\
\hline 1876 & & 17,2 \\
\hline 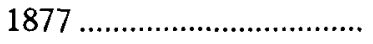 & 21,5 & 22,3 \\
\hline $1878 \ldots \ldots \ldots \ldots \ldots \ldots \ldots \ldots$ & & 20,6 \\
\hline 1879 & & 23,5 \\
\hline 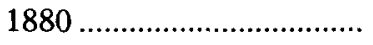 & & 26,0 \\
\hline 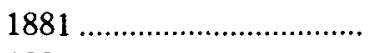 & & 34,2 \\
\hline $1882 \ldots \ldots \ldots \ldots \ldots \ldots$ & & 35,5 \\
\hline $1883 \ldots \ldots \ldots \ldots \ldots$ & & 27,5 \\
\hline 1884 & 23,8 & 24,6 \\
\hline $1885 \ldots \ldots \ldots \ldots \ldots \ldots \ldots \ldots \ldots$ & 21,2 & 23,4 \\
\hline $1886 \ldots \ldots \ldots \ldots \ldots \ldots \ldots \ldots$ & & 25,5 \\
\hline $1887 \ldots \ldots \ldots \ldots \ldots \ldots \ldots \ldots$ & 27,8 & 33,1 \\
\hline 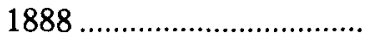 & 29,6 & 38,3 \\
\hline 1889 & 39,4 & 46,1 \\
\hline 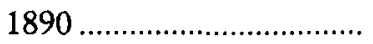 & & 48,4 \\
\hline 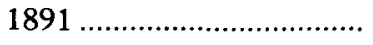 & & 43,7 \\
\hline $1892 \ldots \ldots \ldots \ldots \ldots \ldots \ldots$ & 43,4 & 43,3 \\
\hline 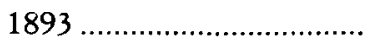 & 30,3 & 30,3 \\
\hline 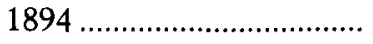 & 34,0 & 34,2 \\
\hline 1895 & 42,3 & 42,5 \\
\hline 1896 & 42,2 & 42,5 \\
\hline 1897 & 43,6 & 43,0 \\
\hline 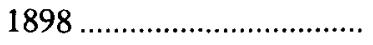 & 50,9 & 50,6 \\
\hline 1899 & 61,3 & 61,7 \\
\hline 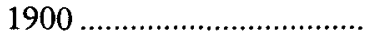 & 65,1 & 65,3 \\
\hline 1901 & 66,2 & 65,3 \\
\hline $1902 \ldots \ldots \ldots \ldots \ldots \ldots \ldots \ldots$ & 75,9 & 75,6 \\
\hline 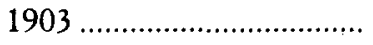 & 78,4 & 78,4 \\
\hline 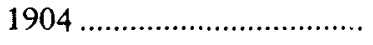 & 86,1 & 86,6 \\
\hline 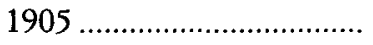 & 109,7 & 90,2 \\
\hline $1906 \ldots \ldots \ldots \ldots \ldots \ldots \ldots$ & 115,7 & 110,8 \\
\hline $1907 \ldots \ldots \ldots \ldots \ldots$ & 110,5 & 108,0 \\
\hline
\end{tabular}




\begin{tabular}{|c|c|c|}
\hline & Totales $M X$ & Mercancias SK \\
\hline 1908. & 78,0 & 78,1 \\
\hline 1909. & 97,1 & 96,8 \\
\hline .......................... & 102,6 & 102,8 \\
\hline $1911 \ldots \ldots$ & 91,0 & 91,6 \\
\hline $1912 \ldots \ldots$ & 95,8 & 95,9 \\
\hline . & 85,4 & 76,3 \\
\hline $1914 \ldots \ldots$ & 9,7 & 41,5 \\
\hline $1915 \ldots \ldots$ & 36,8 & 52,3 \\
\hline 1916 & 42,2 & 82,7 \\
\hline 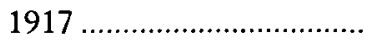 & 94,9 & 114,3 \\
\hline 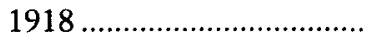 & 137,7 & 109,9 \\
\hline 1919 & 118,1 & 143,7 \\
\hline 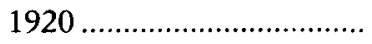 & 197,7 & 247,8 \\
\hline $1921 \ldots \ldots \ldots \ldots \ldots \ldots \ldots \ldots$ & 245,8 & 266,5 \\
\hline $1922 \ldots \ldots \ldots \ldots$ & 153,8 & 150,9 \\
\hline $1923 \ldots \ldots \ldots \ldots \ldots \ldots \ldots$ & 157,1 & 154,9 \\
\hline 1924 & 160,2 & 168,3 \\
\hline $1925 \ldots \ldots \ldots \ldots \ldots$ & 194,9 & 191,3 \\
\hline 1926 & 184,3 & 179,1 \\
\hline 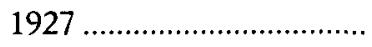 & 163,7 & 155,6 \\
\hline $1928 \ldots \ldots \ldots \ldots \ldots \ldots \ldots \ldots$ & 172,2 & 169,5 \\
\hline 1929 & 184,2 & 183,3 \\
\hline
\end{tabular}

Serie de exportaciones, fuentes oficiales $(M X)$ y reconstrucción $(S K)$

\begin{tabular}{|c|c|c|c|c|c|c|}
\hline & \multicolumn{2}{|c|}{$\begin{array}{c}\text { Mercancias } \\
\text { (millones de dólares) }\end{array}$} & \multicolumn{2}{|c|}{$\begin{array}{c}\text { Metálico } \\
\text { (millones de dólares) }\end{array}$} & \multicolumn{2}{|c|}{$\begin{array}{c}\text { Totales } \\
\text { (millones de dólares) }\end{array}$} \\
\hline & $\begin{array}{l}\text { Mercancias } \\
\qquad M X\end{array}$ & $\begin{array}{l}\text { Mercancias } \\
\text { SK }\end{array}$ & $\begin{array}{l}\text { Metálico } \\
\text { SK }\end{array}$ & $\begin{array}{c}\text { Metales } \\
\text { preciosos MX }\end{array}$ & $\begin{array}{c}\text { Totales } \\
\text { SK }\end{array}$ & $\begin{array}{c}\text { Totales } \\
\text { MX }\end{array}$ \\
\hline $1870 \ldots \ldots \ldots \ldots$ & & 6,4 & 23,8 & & 30,3 & 19,4 \\
\hline $1871 \ldots \ldots \ldots \ldots$ & & 7,8 & 15,0 & & 22,8 & \\
\hline $1872 \ldots \ldots \ldots \ldots$ & 6,6 & 8,3 & 25,6 & 26,2 & 34,0 & 32,8 \\
\hline $1873 \ldots \ldots \ldots \ldots$ & 6,8 & 8,7 & 22,0 & 21,8 & 30,7 & 28,6 \\
\hline $1874 \ldots \ldots \ldots \ldots$ & 7,2 & 10,5 & 19,6 & 20,7 & 30,1 & 27,8 \\
\hline $1875 \ldots \ldots \ldots \ldots$ & & 10,9 & 19,9 & & 30,8 & \\
\hline $1876 \ldots \ldots \ldots \ldots$ & & 10,9 & 23,8 & & 34,7 & \\
\hline $1877 \ldots \ldots \ldots \ldots$ & 6,0 & 10,2 & 21,7 & 20,6 & 31,9 & 26,6 \\
\hline $1878 \ldots \ldots \ldots \ldots$ & 7,6 & 10,0 & 20,7 & 19,6 & 30,6 & 27,2 \\
\hline
\end{tabular}




\begin{tabular}{|c|c|c|c|c|c|c|}
\hline & \multicolumn{2}{|c|}{$\begin{array}{c}\text { Mercancias } \\
\text { (millones de dólares) }\end{array}$} & \multicolumn{2}{|c|}{$\begin{array}{c}\text { Metálico } \\
\text { (millones de dólares) }\end{array}$} & \multicolumn{2}{|c|}{$\begin{array}{c}\text { Totales } \\
\text { (millones de dólares) }\end{array}$} \\
\hline & $\begin{array}{l}\text { Mercancías } \\
\text { MX }\end{array}$ & $\begin{array}{l}\text { Mercancias } \\
\text { SK }\end{array}$ & $\begin{array}{c}\text { Metálico } \\
\text { SK }\end{array}$ & $\begin{array}{c}\text { Metales } \\
\text { preciosos } M X\end{array}$ & $\begin{array}{l}\text { Totales } \\
\text { SK }\end{array}$ & $\begin{array}{c}\text { Totales } \\
\text { MX }\end{array}$ \\
\hline $1879 \ldots \ldots \ldots \ldots$ & 9,5 & 12,1 & 21,4 & 19,9 & 33,6 & 29,4 \\
\hline $1880 \ldots \ldots \ldots \ldots$ & 9,4 & 13,4 & 19,1 & 17,2 & 32,5 & 26,6 \\
\hline $1881 \ldots \ldots \ldots \ldots$ & 10,7 & 13,5 & 16,2 & 15,3 & 29,7 & 26,0 \\
\hline $1882 \ldots \ldots \ldots \ldots$ & 10,7 & 13,5 & 26,1 & 26,1 & 39,6 & 36,9 \\
\hline $1883 \ldots \ldots \ldots \ldots$ & 11,6 & 14,3 & 29,9 & 29,3 & 44,3 & 40,9 \\
\hline $1884 \ldots \ldots \ldots \ldots$ & 11,1 & 14,4 & 28,9 & 29,2 & 43,4 & 40,3 \\
\hline $1885 \ldots \ldots \ldots \ldots$ & 11,2 & 15,8 & 28,0 & 24,4 & 43,8 & 35,6 \\
\hline $1886 \ldots \ldots \ldots \ldots$ & 12,3 & 19,3 & 26,6 & 26,5 & 45,9 & 38,9 \\
\hline $1887 \ldots \ldots \ldots \ldots$ & 13,6 & 22,0 & 22,6 & 23,5 & 44,6 & 37,1 \\
\hline $1888 \ldots \ldots \ldots \ldots$ & 15,8 & 25,8 & 27,1 & 28,7 & 52,8 & 44,5 \\
\hline $1889 \ldots \ldots \ldots \ldots$ & 18,1 & 27,3 & 27,7 & 29,3 & 55,0 & 47,4 \\
\hline $1890 \ldots \ldots \ldots \ldots$ & 22,6 & 34,7 & 22,7 & 30,3 & 57,4 & 53,0 \\
\hline $1891 \ldots \ldots \ldots \ldots$ & 22,0 & 36,3 & 29,6 & 41,1 & 65,8 & 63,2 \\
\hline $1892 \ldots \ldots \ldots \ldots$ & 20,4 & 42,6 & 31,8 & 37,1 & 74,4 & 57,5 \\
\hline $1893 \ldots \ldots \ldots \ldots$ & 17,7 & 38,1 & 17,8 & 25,1 & 55,9 & 42,8 \\
\hline $1894 \ldots \ldots \ldots \ldots . . . . . . .$. & 19,7 & 34,8 & 17,3 & 27,0 & 52,1 & 46,7 \\
\hline $1895 \ldots \ldots \ldots \ldots$ & 21,5 & 41,3 & 21,2 & 34,8 & 62,5 & 56,3 \\
\hline $1896 \ldots \ldots \ldots \ldots$ & 22,7 & 45,8 & 19,3 & 33,2 & 65,1 & 55,9 \\
\hline $1897 \ldots \ldots \ldots \ldots$ & 24,2 & 44,9 & 19,5 & 33,6 & 64,4 & 57,8 \\
\hline $1898 \ldots \ldots \ldots . . . . .$. & 29,4 & 49,2 & 19,3 & 36,0 & 68,5 & 65,4 \\
\hline $1899 \ldots \ldots \ldots \ldots$ & 37,6 & 57,3 & 16,4 & 33,8 & 73,8 & 71,4 \\
\hline $1900 \ldots \ldots \ldots \ldots$ & 32,9 & 56,2 & 20,4 & 39,8 & 76,6 & 72,7 \\
\hline $1901 \ldots \ldots \ldots \ldots$ & 40,1 & 62,3 & 19,0 & 30,4 & 81,3 & 70,5 \\
\hline $1902 \ldots \ldots \ldots \ldots$ & 42,2 & 65,5 & 21,8 & 34,6 & 87,2 & 76,8 \\
\hline $1903 \ldots \ldots \ldots \ldots$ & 47,1 & 72,6 & 21,8 & 39,6 & 94,4 & 86,8 \\
\hline $1904 \ldots \ldots \ldots \ldots$ & 55,4 & 83,1 & 19,6 & 38,3 & 102,6 & 93,6 \\
\hline $1905 \ldots \ldots \ldots$ & 57,0 & 104,0 & 37,7 & 78,5 & 141,7 & 135,6 \\
\hline $1906 \ldots \ldots \ldots \ldots$ & 62,1 & 108,4 & 22,1 & 61,9 & 130,5 & 124,0 \\
\hline $1907 \ldots \ldots \ldots . . . . .$. & 58,5 & 105,5 & 19,5 & 62,1 & 129,0 & 120,6 \\
\hline $1908 \ldots \ldots \ldots \ldots$ & 58,7 & 104,2 & 18,2 & 56,2 & 122,4 & 114,9 \\
\hline $1909 \ldots \ldots \ldots \ldots$ & 70,2 & 115,9 & 19,1 & 59,3 & 135,0 & 129,5 \\
\hline $1910 \ldots \ldots \ldots \ldots$ & 75,1 & 122,5 & 30,0 & 71,2 & 152,5 & 146,3 \\
\hline $1911 \ldots \ldots \ldots \ldots$ & 78,8 & 130,0 & 24,2 & 69,3 & 154,2 & 148,1 \\
\hline $1912 \ldots \ldots \ldots \ldots$ & 84,2 & 137,9 & 23,9 & 65,0 & 161,7 & 149,2 \\
\hline $1913 \ldots \ldots \ldots \ldots$ & & 130,3 & 9,7 & & 140,0 & 153,6 \\
\hline $1914 \ldots \ldots \ldots \ldots$ & & 108,0 & 5,9 & & 113,9 & \\
\hline $1915 \ldots \ldots \ldots \ldots$ & & 132,8 & 4,4 & & 137,2 & \\
\hline
\end{tabular}




\begin{tabular}{|c|c|c|c|c|c|c|}
\hline & \multicolumn{2}{|c|}{$\begin{array}{c}\text { Mercancías } \\
\text { (millones de dólares) }\end{array}$} & \multicolumn{2}{|c|}{$\begin{array}{c}\text { Metálico } \\
\text { (millones de dólares) }\end{array}$} & \multicolumn{2}{|c|}{$\begin{array}{c}\text { Totales } \\
\text { (millones de dólares) }\end{array}$} \\
\hline & $\begin{array}{l}\text { Mercancias } \\
\text { MX }\end{array}$ & $\begin{array}{l}\text { Mercancias } \\
\quad S K\end{array}$ & $\begin{array}{l}\text { Metálico } \\
\text { SK }\end{array}$ & $\begin{array}{c}\text { Metales } \\
\text { preciosos } M X\end{array}$ & $\begin{array}{c}\text { Totales } \\
\text { SK }\end{array}$ & $\begin{array}{l}\text { Totales } \\
\text { MX }\end{array}$ \\
\hline $1916 \ldots \ldots \ldots \ldots$ & & 148,8 & 4,3 & & 153,0 & \\
\hline $1917 \ldots \ldots \ldots \ldots$ & & 204,6 & 7,6 & & 212,3 & 161,0 \\
\hline $1918 \ldots \ldots \ldots \ldots$ & 140,3 & 244,9 & 7,4 & 67,5 & 252,3 & 207,8 \\
\hline $1919 \ldots \ldots \ldots \ldots$ & 140,6 & 252,8 & 3,1 & 62,8 & 255,8 & 203,4 \\
\hline $1920 \ldots \ldots \ldots \ldots$ & 359,0 & 303,4 & 6,3 & 66,7 & 309,7 & 425,6 \\
\hline $1921 \ldots \ldots \ldots \ldots$ & 326,2 & 214,4 & 1,8 & 43,9 & 216,2 & 370,1 \\
\hline $1922 \ldots \ldots \ldots \ldots$ & 260,3 & 243,0 & 5,5 & 53,6 & 248,5 & 313,9 \\
\hline $1923 \ldots \ldots \ldots \ldots$ & 219,8 & 251,0 & 2,3 & 56,8 & 253,3 & 276,6 \\
\hline $1924 \ldots \ldots \ldots \ldots$ & 238,2 & 285,4 & 5,4 & 59,1 & 290,8 & 297,2 \\
\hline $1925 \ldots \ldots \ldots \ldots$ & 270,0 & 307,1 & 4,9 & 67,0 & 312,0 & 337,0 \\
\hline $1926 \ldots \ldots \ldots \ldots$ & 267,9 & 301,1 & 1,4 & 66,4 & 302,5 & 334,3 \\
\hline 1927. & 235,1 & 266,2 & 0,5 & 64,4 & 266,7 & 299,5 \\
\hline $1928 \ldots \ldots \ldots \ldots$ & 216,8 & 231,5 & 0,2 & 68,3 & 231,6 & 285,1 \\
\hline 1929. & 220,8 & 238,9 & 0,1 & 63,9 & 239,0 & 284,7 \\
\hline
\end{tabular}

Comercio de mercancías

\begin{tabular}{lccc}
\hline & $\begin{array}{c}\text { Importaciones } \\
\text { de mercancias }\end{array}$ & $\begin{array}{c}\text { Exportaciones } \\
\text { de mercancias }\end{array}$ & $\begin{array}{c}\text { Balanza de } \\
\text { comercio (visible) }\end{array}$ \\
\hline $1870 \ldots \ldots \ldots \ldots$. & 19,7 & 6,4 & $-13,3$ \\
$1871 \ldots \ldots \ldots \ldots$. & 17,8 & 7,8 & $-10,0$ \\
$1872 \ldots \ldots \ldots \ldots$. & 21,6 & 8,3 & $-13,2$ \\
$1873 \ldots \ldots \ldots \ldots$. & 23,2 & 8,7 & $-14,5$ \\
$1874 \ldots \ldots \ldots \ldots$. & 19,5 & 10,5 & $-9,0$ \\
$1875 \ldots \ldots \ldots \ldots$. & 17,2 & 10,9 & $-6,3$ \\
$1876 \ldots \ldots \ldots \ldots$. & 17,2 & 10,9 & $-6,3$ \\
$1877 \ldots \ldots \ldots \ldots$. & 22,3 & 10,2 & $-12,0$ \\
$1878 \ldots \ldots \ldots \ldots$. & 20,6 & 10,0 & $-10,6$ \\
$1879 \ldots \ldots \ldots \ldots$. & 23,5 & 12,1 & $-11,4$ \\
$1880 \ldots \ldots \ldots \ldots$. & 26,0 & 13,4 & $-12,6$ \\
$1881 \ldots \ldots \ldots \ldots$. & 34,2 & 13,5 & $-20,8$ \\
$1882 \ldots \ldots \ldots \ldots$. & 35,5 & 13,5 & $-22,0$ \\
$1883 \ldots \ldots \ldots \ldots$. & 27,5 & 14,3 & $-13,2$ \\
$1884 \ldots \ldots \ldots \ldots$. & 24,6 & 14,4 & $-10,2$ \\
$1885 \ldots \ldots \ldots \ldots$. & 23,4 & 15,8 & $-7,6$ \\
$1886 \ldots \ldots \ldots \ldots$. & 25,5 & 19,3 & $-6,2$ \\
$1887 \ldots \ldots \ldots \ldots$. & 33,1 & 22,0 & $-11,1$ \\
& & &
\end{tabular}




\begin{tabular}{|c|c|c|c|}
\hline & $\begin{array}{l}\text { Importaciones } \\
\text { de mercancias }\end{array}$ & $\begin{array}{l}\text { Exportaciones } \\
\text { de mercancias }\end{array}$ & $\begin{array}{c}\text { Balanza de } \\
\text { comercio (visible) }\end{array}$ \\
\hline $1888 \ldots \ldots \ldots \ldots$ & 38,3 & 25,8 & $-12,6$ \\
\hline $1889 \ldots \ldots \ldots \ldots$ & 46,1 & 27,3 & $-18,8$ \\
\hline $1890 \ldots \ldots \ldots \ldots$ & 48,4 & 34,7 & $-13,7$ \\
\hline $1891 \ldots \ldots \ldots \ldots$ & 43,7 & 36,3 & $-7,5$ \\
\hline $1892 \ldots \ldots \ldots \ldots$ & 43,3 & 42,6 & $-0,7$ \\
\hline $1893 \ldots \ldots \ldots \ldots$ & 30,3 & 38,1 & 7,8 \\
\hline $1894 \ldots \ldots \ldots \ldots$ & 34,2 & 34,8 & 0,7 \\
\hline $1895 \ldots \ldots \ldots \ldots$ & 42,5 & 41,3 & $-1,2$ \\
\hline $1896 \ldots \ldots \ldots \ldots$ & 42,5 & 45,8 & 3,3 \\
\hline $1897 \ldots \ldots \ldots \ldots$ & 43,0 & 44,9 & 1,9 \\
\hline $1898 \ldots \ldots \ldots \ldots$ & 50,6 & 49,2 & $-1,4$ \\
\hline $1899 \ldots \ldots \ldots \ldots$ & 61,7 & 57,3 & $-4,4$ \\
\hline $1900 \ldots \ldots \ldots \ldots$ & 65,3 & 56,2 & $-9,1$ \\
\hline $1901 \ldots \ldots \ldots \ldots$ & 65,3 & 62,3 & $-3,1$ \\
\hline $1902 \ldots \ldots \ldots \ldots$ & 75,6 & 65,5 & $-10,2$ \\
\hline $1903 \ldots \ldots \ldots \ldots$ & 78,4 & 72,6 & $-5,8$ \\
\hline $1904 \ldots \ldots \ldots \ldots$ & 86,6 & 83,1 & $-3,6$ \\
\hline $1905 \ldots \ldots \ldots \ldots$ & 90,2 & 104,0 & 13,8 \\
\hline $1906 \ldots \ldots \ldots \ldots$ & 110,8 & 108,4 & $-2,4$ \\
\hline $1907 \ldots \ldots \ldots . . . .$. & 108,0 & 105,5 & $-2,5$ \\
\hline $1908 \ldots \ldots \ldots \ldots$ & 78,1 & 104,2 & 26,1 \\
\hline $1909 \ldots \ldots \ldots \ldots$ & 96,8 & 115,9 & 19,1 \\
\hline $1910 \ldots \ldots \ldots \ldots$ & 102,8 & 122,5 & 19,7 \\
\hline $1911 \ldots \ldots \ldots \ldots$ & 91,6 & 130,0 & 38,4 \\
\hline $1912 \ldots \ldots \ldots \ldots$ & 95,9 & 137,9 & 42,0 \\
\hline $1913 \ldots \ldots \ldots \ldots$ & 76,3 & 130,3 & 54,0 \\
\hline $1914 \ldots \ldots \ldots \ldots$ & 41,5 & 108,0 & 66,5 \\
\hline $1915 \ldots \ldots \ldots \ldots$ & 52,3 & 132,8 & 80,5 \\
\hline $1916 \ldots \ldots \ldots \ldots$ & 82,7 & 148,8 & 66,1 \\
\hline $1917 \ldots \ldots \ldots \ldots$ & 114,3 & 204,6 & 90,3 \\
\hline $1918 \ldots \ldots \ldots \ldots$ & 109,9 & 244,9 & 135,0 \\
\hline $1919 \ldots \ldots \ldots \ldots$ & 143,7 & 252,8 & 109,1 \\
\hline $1920 \ldots \ldots \ldots \ldots$ & 247,8 & 303,4 & 55,6 \\
\hline $1921 \ldots \ldots \ldots \ldots$ & 266,5 & 214,4 & $-52,1$ \\
\hline $1922 \ldots \ldots \ldots \ldots$ & 150,9 & 243,0 & 92,1 \\
\hline $1923 \ldots \ldots \ldots \ldots$ & 154,9 & 251,0 & 96,1 \\
\hline $1924 \ldots \ldots \ldots \ldots$ & 168,3 & 285,4 & 117,0 \\
\hline $1925 \ldots \ldots \ldots \ldots$ & 191,3 & 307,1 & 115,8 \\
\hline $1926 \ldots \ldots \ldots \ldots$ & 179,1 & 301,1 & 122,1 \\
\hline $1927 \ldots \ldots \ldots \ldots$ & 155,6 & 266,2 & 110,5 \\
\hline $1928 \ldots \ldots \ldots \ldots$ & 169,5 & 231,5 & 61,9 \\
\hline $1929 \ldots \ldots \ldots \ldots$ & 183,3 & 238,9 & 55,7 \\
\hline
\end{tabular}


Balanza comercial y exportaciones netas de metálico

\begin{tabular}{|c|c|c|}
\hline & $\begin{array}{c}\text { Balanza } \\
\text { del comercio total } \\
\text { (visible }+ \text { invisibles) }\end{array}$ & $\begin{array}{c}\text { Exportaciones } \\
\text { netas de metálico }\end{array}$ \\
\hline 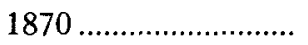 & $-16,2$ & 23,8 \\
\hline $1871 \ldots \ldots \ldots \ldots \ldots \ldots$ & $-12,7$ & 15,0 \\
\hline 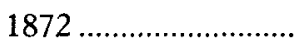 & $-16,5$ & 25,6 \\
\hline 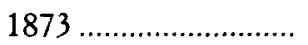 & $-18,0$ & 21,9 \\
\hline 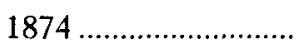 & $-11,9$ & 19,6 \\
\hline 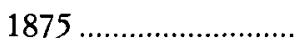 & $-8,8$ & 19,9 \\
\hline 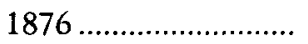 & $-8,9$ & 23,8 \\
\hline 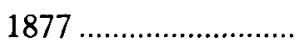 & $-15,4$ & 21,7 \\
\hline $1878 \ldots \ldots \ldots \ldots \ldots \ldots \ldots \ldots$ & $-13,7$ & 20,7 \\
\hline $1879 \ldots \ldots \ldots \ldots \ldots \ldots \ldots \ldots \ldots \ldots \ldots \ldots \ldots \ldots \ldots$ & $-14,9$ & 21,4 \\
\hline $1880 \ldots \ldots \ldots \ldots \ldots \ldots \ldots \ldots$ & $-16,5$ & 19,1 \\
\hline $1881 \ldots \ldots \ldots \ldots \ldots \ldots \ldots \ldots$ & $-25,9$ & 16,2 \\
\hline 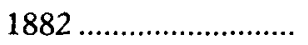 & $-27,4$ & 26,0 \\
\hline $1883 \ldots \ldots \ldots \ldots \ldots \ldots \ldots$ & $-17,3$ & 29,6 \\
\hline 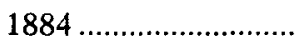 & $-13,9$ & 28,9 \\
\hline 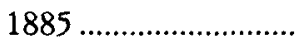 & $-11,2$ & 27,9 \\
\hline $1886 \ldots \ldots \ldots \ldots \ldots \ldots \ldots$ & $-9,3$ & 26,3 \\
\hline $1887 \ldots \ldots \ldots \ldots \ldots \ldots \ldots \ldots$ & $-15,1$ & 22,3 \\
\hline 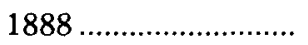 & $-17,2$ & 26,9 \\
\hline $1889 \ldots \ldots \ldots \ldots \ldots \ldots \ldots$ & $-24,3$ & 27,5 \\
\hline $1890 \ldots \ldots \ldots \ldots \ldots \ldots \ldots \ldots \ldots \ldots \ldots$ & $-19,5$ & 22,5 \\
\hline $1891 \ldots \ldots \ldots \ldots \ldots \ldots \ldots \ldots$ & $-11,8$ & 29,4 \\
\hline $1892 \ldots \ldots \ldots \ldots \ldots \ldots$ & $-5,0$ & 31,4 \\
\hline $1893 \ldots \ldots \ldots \ldots \ldots \ldots$ & 4,8 & 17,1 \\
\hline $1894 \ldots \ldots \ldots \ldots \ldots \ldots \ldots$ & $-2,7$ & 16,7 \\
\hline $1895 \ldots \ldots \ldots \ldots \ldots \ldots \ldots$ & $-5,5$ & 20,9 \\
\hline 1896 & $-1,0$ & 19,2 \\
\hline 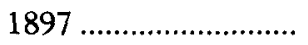 & $-2,4$ & 18,3 \\
\hline $1898 \ldots \ldots \ldots \ldots \ldots \ldots$ & $-6,4$ & 19,2 \\
\hline $1899 \ldots \ldots \ldots \ldots \ldots \ldots \ldots$ & $-10,5$ & 16,4 \\
\hline $1900 \ldots \ldots \ldots \ldots \ldots \ldots \ldots$ & $-15,6$ & 19,3 \\
\hline $1901 \ldots \ldots \ldots \ldots \ldots \ldots \ldots \ldots$ & $-9,6$ & 16,4 \\
\hline $1902 \ldots \ldots \ldots \ldots \ldots \ldots \ldots$ & $-17 ; 7$ & 20,7 \\
\hline 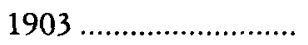 & $-13,7$ & 21,1 \\
\hline $1904 \ldots \ldots \ldots \ldots \ldots \ldots \ldots \ldots \ldots$ & $-12,2$ & 18,7 \\
\hline 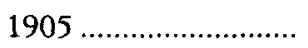 & 4,8 & 17,8 \\
\hline 1906 & $-13,5$ & 11,8 \\
\hline
\end{tabular}


Balanza comercial y exportaciones netas de metálico

\begin{tabular}{|c|c|c|}
\hline & $\begin{array}{c}\text { Balanza } \\
\text { del comercio total } \\
\text { (visible }+ \text { invisibles) }\end{array}$ & $\begin{array}{c}\text { Exportaciones } \\
\text { netas de metálico }\end{array}$ \\
\hline $1907 \ldots \ldots$. & $-13,3$ & 17,5 \\
\hline 1908 & 18,3 & 17,5 \\
\hline 1909 & 9,4 & 18,1 \\
\hline 1910 & 9,4 & 29,7 \\
\hline 1911 & 29,3 & 24,0 \\
\hline 1912 & 32,4 & 23,8 \\
\hline 1913 & 46,4 & 8,2 \\
\hline $1914 \ldots \ldots$ & 62,3 & 5,6 \\
\hline 1915 & 75,3 & 2,8 \\
\hline 1916 & 57,8 & $-2,3$ \\
\hline 1917 & 78,9 & $-17,2$ \\
\hline 1918 & 124,1 & $-21,9$ \\
\hline 1919 & 94,7 & $-9,2$ \\
\hline $1920 \ldots$ & 30,8 & $-15,1$ \\
\hline $1921 \ldots \ldots \ldots \ldots$ & $-78,7$ & $-7,4$ \\
\hline 1922 & 77,0 & $-1,6$ \\
\hline 1923 & 80.6 & $-4,1$ \\
\hline $1924 \ldots \ldots$ & 100,2 & $-0,5$ \\
\hline 1925 & 96,7 & $-5,7$ \\
\hline 1926 & 104,2 & $-6,1$ \\
\hline ............... & 95,0 & $-7,8$ \\
\hline $1928 \ldots \ldots \ldots \ldots \ldots$ & 45,0 & $-5,2$ \\
\hline 1929 & 37,4 & $-8,7$ \\
\hline
\end{tabular}

